\title{
Current state of knowledge on Wolbachia infection among Coleoptera: a systematic review
}

\author{
Lukasz Kajtoch ${ }^{\text {Corresp., }}{ }^{1}$, Nela Kotásková ${ }^{2}$ \\ 1 Institute of Systematics and Evolution of Animals Polish Academy of Sciences, Krakow, Poland \\ ${ }^{2}$ Faculty of Science, University of Ostrava, Ostrava, Czech Republic \\ Corresponding Author: Lukasz Kajtoch \\ Email address: kajtoch@isez.pan.krakow.pl
}

Background. Despite great progress in studies on Wolbachia infection in insects, the knowledge about its relations with beetle species, populations and individuals, and the effects of bacteria on these hosts is still unsatisfactory. In this review we summarize the current state of knowledge about Wolbachia occurrence and interactions with Coleopteran hosts. Methods. An intensive search of the available literature resulted in the selection of 86 publications that describe the relevant details about Wolbachia presence among beetles. These publications were then examined with respect to the distribution and taxonomy of infected hosts and diversity of Wolbachia found in beetles. Sequences of Wolbachia genes (16S rDNA, ftsZ) were used for the phylogenetic analyses. Results. The collected publications revealed that Wolbachia has been confirmed in 204 beetle species and that the estimated average prevalence of this bacteria across beetle species is $38.3 \%$ and varies greatly across families and genera (0-88\% infected members) and is much lower (c. 13\%) in geographic studies. The majority of the examined and infected beetles were from Europe and East Asia. The most intensively studied have been two groups of herbivorous beetles: Curculionidae and Chrysomelidae. Coleoptera harbor Wolbachia belonging to three supergroups: $F$ found in only 3 species, and $A$ and $B$ found in similar numbers of beetles (including some doubly infected); however the latter two were most prevalent in different families. $59 \%$ of species with precise data were found to be totally infected. Single infections were found in $69 \%$ of species and others were doubly- or multiply-infected. Wolbachia caused numerous effects on its beetle hosts, including selective sweep with host mtDNA (found in 3\% of species), cytoplasmic incompatibility (detected in c. $6 \%$ of beetles) and other effects related to reproduction or development (like male-killing, possible parthenogenesis or haplodiploidy induction, and egg development). Phylogenetic reconstructions for Wolbachia genes rejected cospeciation between these bacteria and Coleoptera, with minor exceptions found in some Hydraenidae, Curculionidae and Chrysomelidae. In contrast, horizontal transmission of 
bacteria has been suspected or proven in numerous cases (e.g. among beetles sharing habitats and/or host plants). Discussion. The present knowledge about Wolbachia infection across beetle species and populations is very uneven. Even the basic data about infection status in species and frequency of infected species across genera and families is very superficial, as only c. $0.15 \%$ of all beetle species have been tested so far. Future studies on Wolbachia diversity in Coleoptera should still be based on the Multi-locus Sequence Typing system, and next-generation sequencing technologies will be important for uncovering Wolbachia relations with host evolution and ecology, as well as with other, co-occurring endosymbiotic bacteria. 


\title{
Current state of knowledge on Wolbachia infection among Coleoptera:
} systematic review

\author{
Łukasz Kajtoch $^{1}$, Nela Kotásková ${ }^{2}$ \\ ${ }^{1}$ Institute of Systematics and Evolution of Animals Polish Academy of Sciences, Sławkowska 17, \\ 31-016, Krakow, Poland \\ ${ }^{2}$ Faculty of Science, University of Ostrava, Dvořákova 7, 70103 Ostrava, Czech Republic \\ corresponding author: Łukasz Kajtoch, lukasz.kajtoch@gmail.com
}

\section{Abstract}

Background. Despite great progress in studies on Wolbachia infection in insects, the knowledge about its relations with beetle species, populations and individuals, and the effects of bacteria on these hosts is still unsatisfactory. In this review we summarize the current state of knowledge about Wolbachia occurrence and interactions with Coleopteran hosts.

Methods. An intensive search of the available literature resulted in the selection of 86 publications that describe the relevant details about Wolbachia presence among beetles. These publications were then examined with respect to the distribution and taxonomy of infected hosts and diversity of Wolbachia found in beetles. Sequences of Wolbachia genes (16S rDNA, ftsZ) were used for the phylogenetic analyses.

Results. The collected publications revealed that Wolbachia has been confirmed in 204 beetle species and that the estimated average prevalence of this bacteria across beetle species is $38.3 \%$ and varies greatly across families and genera $(0-88 \%$ infected members) and is much lower (c. $13 \%)$ in geographic studies. The majority of the examined and infected beetles were from Europe and East Asia. The most intensively studied have been two groups of herbivorous beetles: Curculionidae and Chrysomelidae. Coleoptera harbor Wolbachia belonging to three supergroups: $\mathrm{F}$ found in only 3 species, and A and B found in similar numbers of beetles (including some doubly infected); however the latter two were most prevalent in different families. 59\% of species with precise data were found to be totally infected. Single infections were found in $69 \%$ of species and others were doubly- or multiply-infected. Wolbachia caused numerous effects on its beetle hosts, including selective sweep with host mtDNA (found in 3\% of species), cytoplasmic incompatibility (detected in c. $6 \%$ of beetles) and other effects related to reproduction or 
development (like male-killing, possible parthenogenesis or haplodiploidy induction, and egg development). Phylogenetic reconstructions for Wolbachia genes rejected cospeciation between these bacteria and Coleoptera, with minor exceptions found in some Hydraenidae, Curculionidae and Chrysomelidae. In contrast, horizontal transmission of bacteria has been suspected or proven in numerous cases (e.g. among beetles sharing habitats and/or host plants).

Discussion. The present knowledge about Wolbachia infection across beetle species and populations is very uneven. Even the basic data about infection status in species and frequency of infected species across genera and families is very superficial, as only c. $0.15 \%$ of all beetle species have been tested so far. Future studies on Wolbachia diversity in Coleoptera should still be based on the Multi-locus Sequence Typing system, and next-generation sequencing technologies will be important for uncovering Wolbachia relations with host evolution and ecology, as well as with other, co-occurring endosymbiotic bacteria.

\section{Short title Wolbachia among Coleoptera: a review}

\section{Introduction}

The relations between the intracellular $\alpha$-proteobacterium Wolbachia pipientis Hertig 1936 (hereafter Wolbachia) and its hosts from various groups of arthropods and nematodes have been the object of much research and numerous publications (O’Neill et al., 1992; Werren et al., 1995a; Weinert et al. 2015). The majority of these studies have focused on verifying endosymbiotic bacteria occurrence and diversity in various hosts at different levels: i) among selected species sharing a geographic area (e.g. O’Neill et al., 1992; Werren et al., 1995a, 2000), ii) among species inhabiting the same environment or that are ecologically-associated (e.g. Stahlhut et al., 2010), iii) among species from particular taxonomic groups (e.g. Czarnetzki et al., 2004; Lachowska et al., 2010; Sontowski et al., 2015), and iv) within populations of selected taxa (e.g. Stenberg et al., 2004; Mazur et al., 2016). Another branch of research on the relations between Wolbachia and its hosts has focused on host species phylogenetics or population genetics, which is in some cases related to population differentiation and speciation (e.g. Kubisz et al., 2012; Montagna et al., 2014). In this research, Wolbachia is sometimes treated as an additional "marker" - a source of genetic data about the eco-evolutionary relations of its hosts. A 
58

59

60

61

62

63

64

65

66

67

68

69

70

third type of Wolbachia studies has concerned the direct or indirect effects of the infection on host fitness, development or survival at the individual and population levels (e.g. Weeks 2002; O’Neill 2007). Moreover, in a separate branch of research (or in conjunction with the abovementioned types of studies), Wolbachia is often examined directly, mainly with respect to strain diversity, distribution and relations with other strains or different co-existing bacteria (Baldo et al., 2007). All these branches of research have substantially extended the knowledge about the relations between the most widespread intracellular endosymbiont - Wolbachia and its various hosts. Moreover, these studies have been expanded to encompass other bacteria with similar biologies and effects on hosts (like Cardinium, Spiroplasma, Rickettsia) (Zchori-Fein \& Perlman 2004; Goto et al., 2006; Duron et al., 2008; Weinert et al. 2015); however, a great majority of studies are still conducted on Wolbachia (Zug \& Hammerstein, 2012). Recently, the various Wolbachia supergroups have been proposed to belong to several "Candidatus Wolbachia" species (Ramírez-Puebla et al., 2015); however, this approach has been criticized (Lindsey et al., 2016). Due to the uncertain species status of the "Candidatus Wolbachia" and because all previous studies considered these presumed different species as distant supergroups, in this review we have followed the previous Wolbachia taxonomy.

In summary, Wolbachia has been detected in $10-70 \%$ of examined hosts (Hilgenboecker et al., 2008; Zug \& Hammerstein, 2012), depending on the geographical, ecological or taxonomical association of the selected species. Moreover, more detailed studies, at the population level, have shown that infection is not as straightforward as was assumed in the early stages of Wolbachia research. More and more species have been found to be only partially infected, e.g. in only some parts of their ranges or infection was associated with only some phylogenetic lineages (usually correlated with the distribution of mitochondrial lineages) (Clark et al., 2001; Roehrdanz et al., 2006). Furthermore, examples of multiply infected species and individuals have been reported, which has important consequences for the understanding of some of the effects of Wolbachia infection (Malloch et al., 2000; Gurfield, 2016). Wolbachia is known to have numerous effects on its hosts, among which the most interesting and important are those that disturb host reproduction, such as cytoplasmic incompatibility, thelytokous parthenogenesis, feminization of genetic males, male-killing, increased mating success of infected males via sperm competition and the host's complete dependence on bacteria for egg production (for reviews see Werren, 1997; Werren \& O’Neill, 1997 and Stouthamer et al., 1999). Some of these effects are responsible for diversification of host populations and consequently Wolbachia have probably been involved 
90 in speciation (e.g. by the selective sweep of mtDNA or the whole genome of the infected host

91 with the genome of bacteria; Keller et al., 2004; Mazur et al., 2016). This could be another major

92 factor, additional to those already known, responsible for radiation of insects and particularly

93 beetles.

94 There are several reviews summarizing the state of knowledge on Wolbachia infection 95 among various taxonomic groups of nematodes and arthropods. Over the last years, such reviews have been prepared for the following groups: filarial nematodes (Filarioidea) (Taylor \& Hoerauf, 1999; Casiraghi et al., 2001), crustaceans (Crustacea) (Cordaux et al., 2001), spiders (Araneae) (Goodacre et al., 2006; Yun et al., 2010), mites (Acari) (Chasirini et al., 2015), springtails (Collembola) (Czarnetzki et al., 2004), Heteropteran Bugs (Heteroptera) (Kikuchi et al., 2003), ants (Formicidae) (Russell, 2012), wasps (Hymenoptera: Apocrita) (Schoemaker et al., 2002) and butterflies (Lepidoptera) (Tagami et al., 2004). Surprisingly, there is no such review for beetles (Coleoptera), which include large number of diversified taxa, known from various habitats, and whose members belong to all major trophic guilds of animals. Some groups of beetles have been examined with respect to Wolbachia infection, but usually only with a limited coverage of species (e.g. weevils, Curculionidae, Lachowska et al., 2010; leaf beetles; Chrysomelidae, Clark et al., 2001, Jäckel et al., 2013; jewel beetles; Buprestidae, Sontowski et al., 2015 and minute moss beetles, Hydraenidae, Sontowski et al., 2015).

In this review we have summarized the current state of knowledge on the relations between beetles and Wolbachia by referring to all the abovementioned aspects of research. Moreover, we have highlighted future research directions concerning Wolbachia relationships with their diverse Coleopteran hosts.

\section{Survey Methodology}

We searched the scientific literature with Web of Knowledge databases, using the following combination of keywords linked by AND (the Boolean search term to stipulate that the record should contain this AND the next term): "Wolbachia" AND "Coleoptera" and “Wolbachia" AND "beetles". Our final literature search for this analysis was conducted on December 22, 2017. This produced 322 results. Each result was inspected to determine whether or not it contained information on the subject matter. Articles that had no relevance (e.g. any reports that were not about Wolbachia-Coleoptera relations, including those that only had some references to either beetles or bacteria in the citations) were excluded. After the removal of 
121 duplicates, 65 were excluded from the remaining articles $(n=234)$ for not being direct reports

122

123

124

125

126

127

128

129

130

131

132

133

134

135

136

137

138

139

140

141

142

143

144

145

146

147

148

149

150

151

152 about Wolbachia-Coleoptera relations, 44 were excluded because they examined other hosts and only referred to publications on Coleoptera, and 44 others were excluded because they referred to data already presented in previous publications on Coleoptera. The use of two alternative and comprehensive scientific collections should have reduced any biases. Each document was read critically for the information that it contained on Wolbachia-Coleoptera relations, with special reference to answering the study questions listed below. Figure 1 shows a flow diagram for the systematic review following Prisma guidelines (Moher et al., 2009).

We examined the collected data on various aspects of Wolbachia infection in Coleoptera with respect to the following: the i) characteristics of the publications (to determine the scope and progress of studies on Wolbachia) $(\mathrm{n}=86)$, ii) geographic distribution of infected beetle species and populations $(\mathrm{n}=84)$, iii) sampling design (how many sites and individuals were examined) $(n=63)$, iv) characteristics of the markers (genes) used for genotyping the bacteria $(n=82)$ and their hosts $(n=34), v)$ numbers and frequencies of species found to be infected in particular beetle families and genera $(n=58)$, vi) supergroup prevalence in examined taxonomic groups $(n=43)$, vii) strain distribution and diversity in populations and individuals $(n=30)$, vii) effects of Wolbachia on its beetle hosts $(n=39)$. Statistical analyses (Spearman correlation for number of publication across years and for the number of examined and number of infected species, $\mathrm{Chi}^{2}$ test for frequency of supergroups and infected taxa in particular taxonomic groups, Chi2 ANOVA for comparison of single/double/multiple infected taxa, Kruskal-Wallis Z test for infection frequency in Chrysomelidae and Curculionidae) were done in Statistica 11 (Statsoft).

Finally, we downloaded from GenBank (https://www.ncbi.nlm.nih.gov/genbank/) and the Wolbachia MLST database (https://pubmlst.org/wolbachia/) all available sequences of Wolbachia genes found in any species of beetle. We restricted further analyses to the most widely used bacteria genes, i.e. $16 \mathrm{~S} r D N A$ and cell division protein gene $f t s Z$. Because of the different lengths and spans of available sequences, the long parts of the 3' and 5' ends of each gene were trimmed, which resulted in alignments of length $663 \mathrm{bp}$ for $16 \mathrm{~S} r D N A$ and $241 \mathrm{bp}$ for ftsZ. The length of the $f t s Z$ alignment was particularly short as two different sets of primers have been used for its amplification, and its amplicons only overlapped across a relatively short part of the gene. Phylogenetic trees were only reconstructed for unique gene variants found in particular host taxa. Trees were inferred using Maximum Likelihood (ML) implemented in IQ-TREE web server http://www.iqtree.org/ (Trifinopoulos et al., 2016) under the following settings Auto selection of 
153 substitution model, ultrafast bootstrap approximation (UFBoot) (Minh et al., 2013) with 10000

154 iterations, maximum correlation coefficient $=0.99$, single branch test with use of the approximate

155 Likelihood-Ratio Test (SH-aLRT) (Anisimova \& Gascuel, 2006; Guindon et al., 2010) and other 156 default options.

157 The nomenclature of host taxa and their systematic positions throughout the paper follow 158 the articles from which the data was derived.

159 Characterization of Wolbachia infection among Coleoptera

160 Publications

161 The final list of publications concerning data about Wolbachia infection in Coleoptera 162 comprised 86 papers (Supplementary Table 1). The oldest articles with relevant information about 163 Wolbachia infection in beetles were published in 1992 (Campbell et al., 1992; O'Neill et al., 164 1992), and the number of articles since then has increased significantly year by year (Spearman 165 correlation $=0.841$; Fig. 2$)$. The majority of these articles $(60 \%)$ concerned infection in only 166 single beetle species, whereas $19 \%$ discussed infection in multiple species belonging to the same 167 genus, $6 \%$ - multiple species from the same family, 6\% - various species of Coleoptera et al., 168 and a further $9 \%$ - studies on geographic groups of insects that included some, usually random 169 species of beetles (O’Neill et al., 1992; Werren et al., 1995, 2000; Weinert et al. 2015).

$170 \quad$ Most studies were done on Curculionidae (34) and Chrysomelidae (34), following

171 Tenebrionidae (9), Coccinellidae (10) and Sylvanidae (3) (Supplementary Table 1). The members 172 of all other families were investigated in only 1-2 studies. Consequently, 2.5 and 1.6

173 Curculionidae and Chrysomelidae species were respectively examined per article. All species of 174 Hydraenidae and Buprestidae were included in only single articles (Sontowski et al., 2015), 175 whereas limited numbers of species of Coccinellidae and Tenebrionidae were examined in several 176 articles (Hurst et al., 1999; Fialho \& Stevens 1996, 1997, 2000; Majerus et al., 2000; et al., 177 Weinert et al., 2007; Elnagdy et al., 2013; Ming et al., 2015; Goodacre et al., 2015; Kageyama et 178 al., 2015; Li et al., 2015; Li et al., 2016; Dudek et al.; 2017). Wolbachia infection was only 179 studied more than once in 20 species.

Sampling design

The majority of species investigated with respect to Wolbachia infection were from 182 Europe, and a relatively high number of species were from Asia and both Americas, whereas only 
183 ten infected species were from Africa, and three from Australia-Oceania (Fig. 3). A number of

184 publications describing Wolbachia infection in Coleoptera had similar geographic coverages (Fig. 1853 ).

186

187

188

189

190

191

192

193

194

195

196

197

198

199

200

201

202

203

204

205

206

207

208

209

210

211

212

213

Studies were done on samples collected from an average of 5.2 sites and concerned on average 53.0 specimens, or if excluding the most widely studied families Curculionidae and Chrysomelidae, 6.0 sites and 65.1 individuals (Fig. 4). For Curculionidae and Chrysomelidae, these numbers were on average 4.4 and 6.0 sites, respectively, and 40.7 and 70.2 individuals, respectively (Fig. 4). The numbers of sites and individuals examined in particular groups were insignificantly different, with the exception of the numbers of examined individuals in Curculionidae and Chrysomelidae (Fig. 4).

Examined genetic markers

The most often used Wolbachia gene for studies on Coleoptera was $f t s Z$, followed by $h c p A$, wsp and $16 S$ rDNA (Fig. 5). Most studies using $h c p A$ also used other MLST genes, including $f t s Z$. On the other hand, many species were only investigated with either $16 S \mathrm{rDNA}$ or wsp or ftsZ alone. Single studies used groEL (Monochamus alternatus, Aikawa et al., 2009; Tribolium madens, Fialho \& Stevens, 2000) or ITS genes (Tribolium madens, Fialho \& Stevens, 2000). So far, only five studies have used next-generation sequencing technology (Illumina or 454) to detect Wolbachia; two used $16 S$ rDNA for metabarcoding of microbiota (Sitona obsoletus, Steriphus variabilis, White et al., 2015; Aleochara bilineata and Aleochara bipustulata, Bili et al., 2016; Hylobius abietis, Berasategui et al., 2016; Brontispa longissimi, Takano et al., 2017;

Harmonia axyridis, Dudek et al., 2017) and one used shotgun genomic sequencing (Amara alpine, Heintzman et al., 2014). For genotyping of hosts, 52.4\% of studies utilized fragments of COI from mtDNA (usually a barcode fragment of this gene). Fewer studies (23.1\%) analyzed

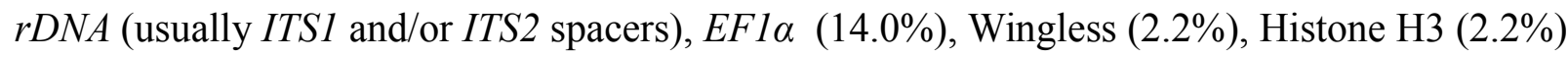
and microsatellites (6.1\%). In Wolbachia-related studies, host genes have been used for several purposes like i) using host DNA as a control for genetic material quality, ii) barcoding for host species identification, iii) phylogenetics, phylogeography and population genetics, iv) estimating co-evolutionary relations between the bacteria and host, and v) detecting some of the effects of Wolbachia on its hosts (like linkage disequilibrium, selective sweep, cytoplasmic incompatibility).

\section{Taxonomic coverage}


214

215

216

217

218

219

220

221

222

223

224

225

226

227

228

229

230

231

232

233

234

235

236

237

238

239

240

241

242

243

244

245

The beetles examined with respect to Wolbachia infection belong to 23 families (Micromalthidae, Gyrinidae, Haliplidae, Noteridae, Dytiscidae, Carabidae, Staphyllinidae, Hydrophilidae, Hydraenidae, Anobiidae, Dermestidae, Buprestidae, Byturidae, Cleridae, Lampyridae, Coccinellidae, Tenebrionidae, Scarabeidae, Meloidae, Sylvanidae, Cerambycidae, Chrysomelidae, Curculionidae). In total 204 beetle species were found to harbor Wolbachia infection; however, the distribution of infected species among families varied markedly. The highest numbers of infected beetle species were found for the Curculionidae (81 species), Chrysomelidae (49 species), Hydraenidae (14 species), Buprestidae (13 species), Coccinellidae (12 species) and Dytiscidae (8 species) (Fig. 6). In all other families only 1-3 species were reported to harbor Wolbachia (Supplementary Table 1). However, these numbers are biased by the low number of articles (studies) dealing with members of particular beetle families (see above).

Considering infection across beetle genera, the most richly infected genera were Altica (Chrysomelidae, 17 species), Naupactus (Curculionidae, 11 species), Hydraena (Hydraenidae, 8 species) and Agrilus (Buprestidae, 6 species) (Supplementary Table 1). In total, 49 genera were found to have infected members (Supplementary Table 1, Table 1). The infection in Coleoptera was estimated at $38.3 \%$ of examined species; however, the proportion of infected species varied greatly between families and genera. At the family level the infection frequency was from $10.5 \%$ (Tenebrionidae) to 100\% (Noteridae) (Goodacre et al., 2015, Sontowski et al., 2015); however when considering only families for which more than 30 species were investigated (e.g. Clark et al., 2001; Lachowska-Cierlik et al.; 2010, Rodriguer et al.; 2010a, Kondo et al.; 2011, Jäckel et al., 2013; Sontowski et al.; 2015, Kawasaki et al., 2016), infection was found in up to $63 \%$ of species (Hydraenidae) (Table 1). At lower taxonomic levels, Wolbachia was found in 25\% of Diabroticite (Chrysomelidae; Clark et al., 2001), 14.3-16.7\% of Bruchina (Chrysomelidae; Kondo et al., 2011), 34.8\% of Scolytinae (Curculionidae, Kawasaki et al., 2016) and 16.7\% of Curculioninii (Toju et al., 2013). Among 54 genera in which Wolbachia infection was examined for at least 2 species, 12 genera were completely uninfected, while 6 genera were completely infected (Table 1). If considering only genera with at least 5 verified species, Wolbachia was found in 0\% (Acmaeodera; Buprestidae; Sontowski et al., 2015) to 88\% of species (Altica, Chrysomelidae; Jäckel et al., 2013). There was only a marginally negative and insignificant correlation between the number of examined and number of infected species $(R=-0.078)$. If considering only the most widely examined families, Chrysomelidae and Curculionidae, the 
246 difference in infection frequency between these two groups was insignificant $(Z=-1.656$,

$247 \mathrm{P}=0.098)$. Geographic studies on Wolbachia prevalence in insects have found much lower

248 frequencies of infection in Coleoptera species: the bacterium was found in only $10.5 \%$ of beetles

249 from Panama and 13.5\% of beetles from North America (Werren et al., 1995a, 2000).

250 Wolbachia diversity

251 Among the various beetle species, Wolbachia strains belonged to three supergroups (A, B 252 and F). However, they occurred at very different proportions in different groups of beetles, and 253 these differences were significant $\left(\mathrm{Chi}^{2}=98.78, \mathrm{P}=0.000\right)$. Overall, the proportion of beetle 254 species found to be infected with Wolbachia strains belonging to supergroups A or B was similar, 255 with approx. 12\% of all species harboring either supergroup (either as single infections in 256 different species or populations or as multiple infections within individuals) (Fig. 7), whereas 257 supergroup F was found in only 3 beetle species: Agrilus araxenus and Lamprodila mirifica (both 258 Buprestidae; Sontowski et al., 2015) and Rhinocyllus conicus (Curculionidae; Campbell et al., 259 1992). In the four groups of beetles with the highest numbers of examined and infected species, 260 the distributions of supergroups varied: in Buprestidae, a similar numbers of species were 261 infected by supergroups A and B (all singly infected), with a relatively high proportion of F 262 infected species (Sontowski et al., 2015). In contrast, in Hydraenida, supergroup A dominated 263 over supergroup B (Sontowski et al., 2015). This was also the case in Chrysomelidae, with some 264 species infected by both strains (Kondo et al., 2011,; Jäckel et al., 2013; Kolasa et al., 2017). The 265 most varied infections were observed in Curculionidae, with supergroup B dominating, a 266 presence of taxa infected by both A and B supergroups, and a single species infected by F 267 supergroup (Lachowska-Cierlik et al.; 2010, Rodriguer et al., 2010a; Kawasaki et al., 2016) (Fig. 268 7). Considering the frequency of infected specimens in the examined beetle species represented 269 by the available data $(\mathrm{N}=106), 63$ species were reported to be totally infected (all individuals possessed Wolbachia), whereas 43 species had this bacterium in only some individuals (if exclude Chrysomelidae and Curculionidae: 8 and 15 species, respectively) (Fig. 8). The same

272 calculated for Chrysomelidae resulted in 17 and 10 species, respectively, and for Curculionidae in 27338 and 18 species, respectively (Fig. 8). These differences between these values (between these 274 groups of species $)$ were significant $\left(\mathrm{Chi}^{2}=72.03, \mathrm{P}=0.000\right)$. A single Wolbachia strain was 275 observed in 43 species (species with available data $\mathrm{N}=62$ ), whereas two strains were reported in 27610 species (Byturus tomentosus, Malloch et al., 2000; Altica quercetorum, Jäckel et al., 2013; 277 Callosobruchus chinensis, Okayama et al., 2016; Chelymorpha alternans, Keller et al., 2004; 
278

279

280

281

282

283

284

285

286

287

288

289

290

291

292

293

294

295

296

297

298

299

300

301

302

303

304

305

306

307

308

309

Crioceris quaterdecimpunctata and Crioceris quinquepunctata, Kolasa et al., 2017; Adalia

bipunctata, Majerus et al., 2000; Polydrusus inustus, Kajtoch et al., 2012; Cyanapion afer and C. spencii, Kajtoch et al., 2017) and multiple infection in a further 9 species (Callosobruchus chinensis, Kondo et al., 2002; Diabrotica barberi, Roehrdanz \& Levine, 2007; Conotrachelus nenuphar, Zhang et al., 2010; Pityogenes chalcographus, Arthofer et al., 2009; Xyleborus dispar and Xylosandrus germanus, Kawasaki et al., 2016) (Fig. 8). In Chrysomelidae (N=22) these numbers were 12, 5 and 5, respectively and in Curculionidae $(\mathrm{N}=37), 30,3$ and 4, respectively (Fig. 8). The numbers of single, double and multiple infected individuals in these groups of beetles differed insignificantly $\left(\mathrm{Chi}^{2} \mathrm{ANOVA}=2.364, \mathrm{P}=0.307\right)$.

Effects on hosts

Wolbachia affected beetle hosts in several ways. Linkage disequilibrium and/or selective sweep between bacteria and host genomes (usually with host mtDNA) were detected in 6 species (3\% or 9\% if excluding Chrysomelidae and Curculionidae): 2 (4\%) Chrysomelidae (Altica lythri, Jäckel et al., 2013; Aphthona nigriscutis, Roehrdanz et al., 2006) and 4 (5\%) Curculionidae (Eusomus ovulum, Mazur et al., 2016; Naupactus cervinus, Rodriguero et al., 2010b, Polydrusus inustus, Polydrusus pilifer, Kajtoch et al., 2012). Cytoplasmic incompatibility was detected or suspected but unconfirmed in 12 (6\% or $18 \%$ if excluding Chrysomelidae and Curculionidae) Coleoptera: 6 (13\%) Chrysomelidae (Chelymorpha alternans, Keller et al., 2004, Diabrotica barberi, Roehrdanz \& Levine 2007, et al.,Diabrotica virgifera virgifera, Giordano et al., 1997; Callosobruchus chinensis, Kondo et al., 2002; Callosobruchus analis, Numajiri et al., 2017; Brontispa longissimi, Takano et al., 2017), 3 (4 \%) of Curculionidae (Cossomus sp., Zhang et al., 2010; Hypothenemus hampei, Mariño et al., 2017, Xylosandrus germanus, Kawasaki et al., 2016), 1 of Sylvanidae (Oryzaephilus surinamensis, Sharaf et al., 2010) and 1 of Tenebrionidae (Tribolium confusum, Li et al., 2016, Ming et al., 2015). Horizontal transfer of Wolbachia was detected or suspected in 26 species of Coleoptera (13\% or 39\% if excluding Chrysomelidae and Curculionidae) - 16 (33\%) species of Chrysomelidae (several species of Altica, Jäckel et al., 2013, Crioceris quaterdecimpunctata and Crioceris quinquepunctata, Kolasa et al., 2017) and 10 (14\%) species of Curculionidae (members of Euwallacea, Xyleborus, Xylosandrus, Xyleborinus schaufussi and Taphrorychus bicolor, Kawasaki et al., 2016, Polydrusus and Parafoucartia squamulata, Kajtoch et al., 2012; Sitophilus oryzae and S. zaemais, Carvalho et al., 2014). Other effects of Wolbachia on beetles included the following: i) transfer of bacteria genes to the autosomes of the host (so far detected only for Monochamus alternatus, Cerambycidae, Aikawa 
310 et al., 2009 and Callosobruchus chinensis, Chrysomelidae, Nikoh et al., 2008); ii) coexistence of

311 Wolbachia with Rickettsia (Calvia quattuordecimguttata, Coccidula rufa, Coccinella

312 septempunctata, Halyzia sedecimguttata, Rhizobius litura, Weinert et al., 2007; Sitona obsoletus,

313 White et al., 2015; Micromalthus debilis, Perotti et al., 2016) in the host or with Spiroplasma

314 (Chilocorus bipustulatus, Weinert et al., 2007; Aleochara bipustulata, Bili et al., 2016) or with

315 both (Adalia bipunctata, Majerus et al., 2000, Harmonia axyridis, Dudek et al., 2017; Curculio

316 sikkimensis, Toju \& Fukatsu, 2011; Aleochara bilineata, Bili et al., 2016); iii) induction and

317 reinforcement of parthenogenesis, however this effect had weak support and had other possible

318 alternative explanations (numerous species of Naupactini, Rodriguer et al., 2010a and Eusomus

319 ovulum, Mazur et al., 2016; all Curculionidae; Micromalthus debilis, Perotti et al., 2016); iv)

320 possible induction of haplodiploidy (Euwallacea interjectus, Euwallacea validus, Curculionidae,

321 Kawasaki et al., 2016); v) male-killing (Tribolium madens, Tenebrionidae, Fialho \& Stevens,

322 2000); vi) necessity of infection for egg development (Otiorhynchus sulcatus, Curculionidae, Son

323 et al., 2008; Coccotrypes dactyliperda, Zchori-Fein et al., 2006); vii) populations evolving

324 towards endosymbiont loss and repeated intraspecific horizontal transfer of Wolbachia

325 (Pityogenes chalcographus, Curculionidae, Arthofer et al., 2009), viii) fitness decline in infected

326 beetles (Callosobruchus analis, Numajiri et al., 2017), ix) modification of sperm (Chelymorpha

327 alternans, Clark et al., 2008), x) down-regulation of defense genes in host plants (Diabrotica

328 virgifera virgifera on maize, Barr et al., 2010).

Phylogenetic relations

The tree reconstructed for $16 S \mathrm{rDNA}$ included 52 sequences from bacteria found in 45

host beetle species. This tree included three major lineages, with separate clusters of Wolbachia sequences belonging to A, B and F supergroups (Supplementary Fig. 1). F supergroup was represented by a single sequence from Rhinocyllus conicus (Curculionidae) (Supplementary Fig.

1). Sequences assigned to supergroup A (based on information available in the articles) were

found to be polyphyletic. Some $16 S$ sequences from Xylosandrus spp. and Curculio spp.

336 (Curculionidae), or Oreina cacaliae and Galeruca tanaceti (Chrysomelidae) clustered as a sister 
The tree reconstructed for $f t s Z$ included 131 sequences found in 114 host beetle species.

341

The fts $Z$ phylogenetic tree resulted in a topology similar to that of $16 \mathrm{~S} r D N A$ - it included groups of sequences belonging to A, B and F supergroups (Supplementary Fig. 2). Supergroup F was represented by Agrilus araxenus and Sphaerobothris aghababiani (both Buprestidae). Moreover, the supergroup B clade was divided into two clusters, among which one included a small group of sequences found in four beetle hosts: Chelymorpha alternans (Chrysomelidae), Eurymetopus fallax, Sitophilus oryzae and Conotrachelus nenuphar (all three Curculionidae) (Supplementary Fig. 2). Also in this gene, the genetic variation of sequences belonging to supergroup A was much lower, and only a few sequences were highly diverged (e.g. strains of Callosobruchus chinensis, Chrysomelidae; Tribolium confusum, Tenebrionidae or Polydrosus pilosus, Curculionidae) (Supplementary Fig. 2). There was also one slightly distinct clade that mainly consisted of bacteria sequences found in some Hydraenidae, Curculionidae and Chrysomelidae (Supplementary Fig. 2).

The abovementioned phylogenetic reconstructions of the relations among Wolbachia strains identified on the basis of polymorphism of several genes show that there is no strict correlation between host phylogeny and bacterial strain relationships. Even in studies that covered multiple related species (e.g. those belonging to the same genus), evidence for direct inheritance of Wolbachia strains from common ancestors is restricted to Hydraenidae (Sontowski et al., 2015) and some species of Oreina (Montagna et al., 2014) or Curculio (Toju et al., 2013). In the case of Altica, the data show that cospeciation was rare and restricted to a few recently diverged species (Jäckel et al., 2013). In contrast, there are numerous examples of phylogenetically related beetle species possessing different Wolbachia strains (e.g. Lachowska et al., 2010). It is also often the case among related species that some are infected, whereas others not (Crioceris, Kubisz et al., 2012; Oreina, Montagna et al., 2014; Cyanapion, Kajtoch et al., 2017); so any assumption that the bacteria were inherited from a common ancestor would also need to consider multiple losses of infection. The latter phenomenon is probable; however, there is no direct evidence from natural populations, at least in studies on beetles, of Wolbachia disappearing over time. Some exemplary studies that found Wolbachia present in related species, after detailed examination, rejected the idea that bacteria was inherited from a common ancestor. This was because different host species harbored unrelated stains (e.g. among weevils, Lachowska et al., 2010, Rodriguer et al., 2010a) or in cases where strains were identical or similar, the hosts were not phylogenetically close to each other (e.g. Crioceris, Kubisz et al., 
372 2012). Finally, there is evermore proof of horizontal Wolbachia transmission via different

373 mechanisms, such as via predators, parasitoids, common habitat or foraging on the same host

374 plants (Huigens et al., 2004; Stahlhut et al., 2010; Caspi-Fluger et al., 2012; Ahmed et al., 2015;

375 Kolasa et al., 2017). Studies on beetles have mainly provided indirect evidence of such

376 transmissions. There are known groups of species that inhabit the same environments and share

377 the same or very similar Wolbachia strains, e.g. steppic weevils from East-central Europe (Mazur

378 et al., 2014) and bark beetles in Japane (Kawasaki et al., 2016). Recently, evidence for has also

379 appeared for the role of host plants in bacteria spread - Wolbachia DNA was detected in two

380 species of Crioceris leaf beetles and in their host plant - Asparagus spp. (Kolasa et al., 2017).

381 Finally, in light of the proposed "Candidatus Wolbachia" species, the summarized

382 phylogenetic relations among Wolbachia strains infecting various beetles indicate that the

383 taxonomic distinctiveness of supergroups is inconclusive (Ramírez-Puebla et al., 2015; Lindsey

384 et al., 2016). First, beetles generally harbor members of supergroups A and B, and only

385 occasionally members of supergroup F. Therefore, it is not possible to make any conclusions

386 about broader Wolbachia taxonomy based only on Wolbachia strains found in Coleoptera.

387 However, there are numerous examples of beetle hosts harboring both supergroups, including

388 beetles in which some Wolbachia genes are of supergroup A origin, while others are of

389 supergroup B origin; this indicates that recombination between strains belonging to different

390 supergroups is quite frequent. This is evidence against the designation of the "Candidatus

391 Wolbachia" species, at least with respect to members of supergroup A and B.

392 Current gaps and future endeavors

The present knowledge on Wolbachia infection across beetle species and populations is very uneven. Even the basic data about infection statuses in species and frequencies of infected species across genera and families is superficial, as there are only c. 200 beetle species known to be infected. This means that if $38 \%$ is the average frequency of infection among beetle species, then only c. 530 species have been tested so far. This is merely c. $0.15 \%$ of the total number of beetles, which is estimated to be around 360000 species (Farrell, 1998; Bouchard et al., 2009). We know even less at the population level, as the majority of beetle species have only had single 400 individuals tested for Wolbachia infection (e.g. Lachowska et al., 2010, Sontowski et al., 2015). 401 These very basic screens have probably underestimated the number of infected species because of 402 false-negative results obtained for species with low or local infection in populations. There is also 
403 another and important cause that should be mentioned - low titer infections that are under the 404 detection limit of conventional PCR (e.g., Arthofer et al., 2009; Schneider et al., 2013). On the 405 other hand, these preliminary estimates could have overestimated the real number infected 406 beetles, as sampling in these studies was rarely random and most often focused on specific 407 groups, e.g. on genera for which preliminary data suggested the presence of Wolbachia infection. 408 Indeed, an intensive search of Wolbachia infection across hundreds of beetle species from Europe 409 suggested a lower infection rate - c. $27 \%$ to be infected (Kajtoch et al., unpublished). Also, 410 knowledge about infection at the geographic scale is very uneven, and only Europe and Asia 411 (basically China and Japan) have been relatively well investigated. There is a huge gap in the 412 knowledge for African, Australian and Oceanian beetles, where a high diversity of beetles exists 413 and probably a similar diversity of Wolbachia could be expected (e.g. compared to preliminary 414 data available from Central and South America (Werren et al., 1995; Rodriguer et al., 2010a)). only single genetic markers, and often different genes were sequenced for different taxa. This precludes complex analysis of Wolbachia diversity across all tested beetle hosts. This has changed since 2006, since Baldo et al. (2006) proposed Multilocus Sequence Typing (MLST), which is based on the genotyping of five housekeeping genes, usually in conjunction with wsp sequencing. MLST is and should remain a sufficient way to understand basic Wolbachia diversity. On the other hand, to fully understand Wolbachia relations among strains and supergroups (or presumed species), between Wolbachia and its hosts and especially between Wolbachia and other microorganisms, amplicon-sequencing (e.g. 16S rDNA) or genomesequencing are needed. This could be achieved thanks to the development of next-generation sequencing technologies (NGS). Surprisingly, despite fast development of NGS in the last years, very few studies have used this technology for studying Wolbachia in beetle populations. For example, five studies sequenced $16 \mathrm{~S}$ amplicons generated from microbiota and detected Wolbachia (White et al., 2015; Bili et al., 2016; Berasategui et al., 2016; Takano et al., 2017; Dudek et al., 2017). The only study that utilized shotgun sequencing was executed for other purposes and only accidentally showed Wolbachia genes in examined species (Heintzman et al., 2014). NGS is probably the best prospect for studies on Wolbachia infection and diversity, and will help to answer most current riddles and issues. 
435 few studies prove or suggest e.g. cytoplasmic incompatibility, male-killing or other effects on the 436 development of selected beetles (Clark et al., 2001; Keller et al., 2004 Roehrdanz et al., 2006 437 Roehrdanz \& Levine 2007 Sharaf et al., 2010 Zhang et al., 2010; Jäckel et al., 2013; Ming et al., 438 2015; Kawasaki et al., 2016; Li et al., 2016; Mariño et al., 2017; Numajiri et al., 2017; Takano et 439 al., 2017). It is very probable that this bacteria has large and frequent effects on beetle 440 reproduction and is consequently partially responsible for beetle radiation, at least in some 441 taxonomic groups, geographic areas or habitats. Also very few studies have shown data on 442 linkage disequilibrium and selective sweep between bacteriium and host genomes (Roehrdanz et 443 al., 2006; Rodriguero et al., 2010b; Kajtoch et al., 2012; Jäckel et al., 2013; Mazur et al., 2016).

444 These effects could also have probably been involved in speciation of numerous beetles.

445 Moreover, this phenomenon could have serious implications for beetle barcoding, as selective 446 sweep is known to reduce mitochondrial diversity in its hosts and therefore could decrease the 447 number of identified species (Hurst \& Jiggins, 2005). On the other hand, cytoplasmic 448 incompatibility can lead to the origin of highly diverged phylogenetic mitochondrial lineages 449 within species, which would increase the number of identified taxa (Smith et al., 2012). Also 450 here, NGS technologies will enable more sophisticated analyses of these genetic relations and their effects (e.g. by the sequencing of transcriptomes for physiological studies or by genotypingby-sequencing for phylogenetic studies). Genotyping with NGS should also verify whether the 453 recent assumption that different supergroups are indeed "Candidatus Wolbachia" species is correct or not (Ramírez-Puebla et al., 2015; Lindsey et al., 2016).

Only very preliminary results suggest Wolbachia was not only transmitted vertically, but that it could also have spread horizontally (Jäckel et al., 2013; Carvalho et al., 2014; Kawasaki et al., 2016; Kolasa et al., 2017; Mazur et al., 2017). Horizontal transmission was considered as an event that happens in evolutionary timescales. Only recently, Schuler et al. (2013) showed that such a transfer can happen within a few years after arrival of a new strain. In light of the general lack of cospeciation between bacteria and beetles, horizontal transmission must be a highly underestimated phenomenon. Horizontal transmission of Wolbachia among beetles cannot be confirmed without considering other coexisting insects that can mediate transmission, such as predators, parasitoids or beetle prey. Moreover, other arthropods that share habitats with beetles, e.g. phoretic ticks (Hartelt et al., 2004) and nematodes (Casiraghi et al., 2001), need to be examined. Finally, host plants are promising objects of studies on Wolbachia transmission across beetle populations (Kolasa et al., 2017), as phloem is probably an important mediator of this 
467 bacteria's spread across insect populations (DeLay, 2012; Li et al., 2016). Concerning

468 transmission - another very interesting topic is the transfer of Wolbachia genes into host genomes

469 (Dunning Hotopp et al., 2007; Koutsovoulos et al., 2014; Funkhouser-Jones et al., 2015). This

470 issue has only been reported twice for beetle hosts so far (Nikoh et al., 2008; Aikawa et al.,

471 2009). This problem could be important as if such transfers are frequent, simple testing of

472 Wolbachia presence in a host based on single or even several gene sequencing could overestimate

473 the number of truly infected species, populations or individuals.

474 Finally, a very interesting topic for future studies is the examination of the presence of

475 other intracellular and symbiotic bacteria (like Cardinium, Spiroplasma, Rickettsia) in Coleoptera

476 and their relations, both with the host and Wolbachia. So far, only seven studies have found

477 Wolbachia with Rickettsia and/or Spiroplasma together in beetle hosts (Majerus et al., 2000;

478 Weinert et al., 2007; Toju \& Fukatsu 2011; White et al., 2015; Perotti et al., 2016; Bili et al.,

479 2016; Dudek et al., 2017). Preliminary results suggest that there is some balance in the number of

480 these bacteria, probably caused by competition within host cells (Goto et al., 2006). A recent

481 summary of the presence of these bacteria in insects showed that Rickettsia has been found in

482 single species of Micromalthidae, Staphylinidae, Buprestidae, Coccinellidae and Curculionidae

483 (Werren et al., 1994; Lawson et al., 2001; Weinert et al., 2007; Toju \& Fukatsu 2011; White et al.,

484 2015; Perotti et al., 2016; Bili et al., 2016), Spiroplasma in some species of Staphylinidae,

485 Coccinellidae and Curculionidae (Majerus et al., 1998; Hurst et al., 1999; Tinsley \& Majerus,

486 2006; Weinert et al., 2007; Toju \& Fukatsu 2011; Bili et al., 2016), and Cardinium has not been

487 detected so far in any beetle species (Zchori-Fein et al., 2004). The coexistence of different

488 endosymbiotic bacteria and their effects on hosts should also be investigated with NGS

489 technologies, which are able to detect bacteria in numerous hosts (e.g. individuals) at once and

490 estimate prevalence of bacteria in various hosts or different tissues. NGS has already been proven

491 to be a powerful tool for detecting undescribed bacteria (e.g. it allowed the identification of new

492 Alphaproteobacteria in Brontispa longissimi; Takano et al., 2017). Different endosymbiotic

493 bacteria could have either similar or contrasting effects on beetle species, populations and

494 individuals and could be the greatest overlooked phenomenon in the evolution and ecology of

495 Coleoptera.

496 In our opinion, beetles are still an insufficiently examined group of Wolbachia hosts,

497 especially considering their systematic and ecological diversity. All issues in studies on

498 Wolbachia in Coleoptera are generally the same as in other hosts of these bacteria, or vice versa; 
499 there is no issue that has been or is being studied on Wolbachia infection in other (non-beetle)

500 hosts that could not also be examined in beetle hosts. And the extraordinary diversity of beetles

501 (with respect to their diverse systematics at various taxonomic levels, complex phylogenetic

502 relations and extensive ecological relations with each other and numerous other species) makes

503 this group an excellent target for Wolbachia studies. The presented summary about Wolbachia

504 infection in beetles shows that despite numerous studies, there are still many issues that need to

505 be investigated. We hope that this systematic review will facilitate various future studies on

506 Wolbachia infection among beetles.

507 Acknowledgements

508 We kindly thank Prof. Lech Borowiec for providing the pictures of beetles from his

509 ICONOGRAPHIA COLEOPTERORUM POLONIAE (C) Copyright by Prof. Lech Borowiec,

510 Wrocław 2007-2014, Department of Biodiversity and Evolutionary Taxonomy, University of

511 Wroclaw, Poland)], which were used for preparation of the graphics. We are grateful to

512 anonymous Reviewers for all their comments and suggestions, which allowed for a great

513 improvement of the manuscript.

\section{References}

Ahmed MZ, Li SJ, Xue X, Yin XJ, Ren SX, Jiggins FM, Greeff JM, Qiu BL. 2015. The Intracellular bacterium Wolbachia uses parasitoid wasps as phoretic vectors for efficient horizontal transmission. PLOS Pathogens 11:19 pp. DOI 10.1371/journal.ppat.1004672

Aikawa T, Anbutsu H, Nikoh N, Kikuchi T, Shibata F, Fukatsu T. 2009. Longicorn beetle that vectors pinewood nematode carries many Wolbachia genes on an autosome. Proceedings of the Royal Society B: Biological Sciences 276:3791-3798. DOI 10.1098/rspb.2009.1022.

Anisimova M, Gascuel O. 2006. Approximate likelihood-ratio test for branches: a fast, accurate, and powerful alternative. Systematic Biology 55: 539-552. DOI 10.1080/10635150600755453.

Arthofer W, Riegler M, Avtzis D, Stauffer C. 2009. Evidence for low-titre infections in insect symbiosis: Wolbachia in the bark beetle Pityogenes chalcographus (Coleoptera, Scolytinae). Environmental Microbiology 11: 1923-33. DOI: 10.1111/j.1462-2920.2009.01914.x.

Baldo L, Werren JH. 2007. Revisiting Wolbachia supergroup typing based on WSP: spurious lineages and discordance with MLST. Current Microbiology 55: 81-87. DOI 10.1007/s00284007-0055-8.

Baldo L, Hotopp JCD, Jolley KA, Bordenstein SR, Biber SA, Choudhury RR, Hayashi C, Maiden MCJ, Tettelin H, Werren JH. 2006: Multilocus sequence typing system for the 
531 Endosymbiont Wolbachia pipientis. Applied and Environmental Microbiology 72: 7098-7110.

532 DOI 10.1128/AEM.00731-06.

533 Barr KL, Hearne LB, Briesacher S, Clark TL, Davis GE. 2010. Microbial Symbionts in

534 Insects Influence Down-Regulation of Defense Genes in Maize. PLoS ONE 5: e11339. DOI:

535 10.1371/journal.pone.0011339.

536 Berasategui A, Axelsson K, Nordlander G, Schmidt A, Borg-Karlson A-K, Gershenzon J, 537 Terenius O, Kaltenpoth M. 2016. The gut microbiota of the pine weevil is similar across Europe 538 and resembles that of other 649 conifer beetles. Molecular Ecology 25: 4014-4031. DOI:

$53910.1111 / \mathrm{mec} .14186$.

540 Bili M, Cortesero AM, Mougel C, Gauthier JP, Ermel G, Simon JC, Outreman Y, Terrat S, 541 Mahéo F, Poinsot D. 2016. Bacterial Community Diversity Harboured by Interacting Species. 542 PLoS ONE 11: e0155392. DOI:10.1371/journal.pone.0155392.

543 Bouchard P, Grebennikov VV, Smith ABT, Douglas H. 2009. Biodiversity of Coleoptera In:

544 Foottit RG, Adler PH, eds. Insect biodiversity: science and society. Oxford: Blackwell

545 Publishing, 265-301.

546 Campbell BC, Bragg TS, Turner C E. 1992. Phylogeny of symbiotic bacteria of four weevil 547 species (Coleoptera: Curculionidae) based on analysis of 16s ribosomal DNA. Insect

548 Biochemistry and Molecular Biology 22:415-421. DOI 10.1016/0965-1748(92)90136-3.

549 Casiraghi M, Anderson TJ, Bandi C, Bazzocchi C, Genchi C. 2001. A phylogenetic analysis 550 of filarial nematodes: comparison with the phylogeny of Wolbachia endosymbionts. Parasitology 551 122:93-103. DOI:10.1017/S0031182000007149.

552 Chaisiri K, McGarry JW, Morand S, Makepeace B. 2015. Symbiosis in an overlooked 553 microcosm: a systematic review of the bacterial flora of mites. Parasitology FirstView, 1-11.

554 Caspi-Fluger A, Inbar M, Mozes-Daube N, Katzir N, Portnoy V, Belausov E, Hunter MS, 555 Zchori-Fein E. 2012. Horizontal transmission of the insect symbiont Rickettsia is plant556 mediated. Proceedings of the Royal Society B: Biological Sciences 279:1791-1796. DOI 557 10.1098/rspb.2011.2095.

558 Chafee ME, Funk DJ, Harrison RG, Bordenstein SR. 2010. Lateral phage transfer in obligate 559 intracellular bacteria (Wolbachia): Verification from natural populations. Molecular Biology and 560 Evolution 27: 501—505. DOI: 10.1093/molbev/msp275.

561 Chen SJ, Lu F, Cheng JA, Jiang MX, Way MO. 2012. Identification and Biological Role of the 562 Endosymbionts Wolbachia in Rice Water Weevil (Coleoptera: Curculionidae). Environmental 563 Entomology 41:469-477. DOI 10.1603/EN11195.

564 Clark ME, Bailey-Jourdain C, Ferree PM, England SJ, Sullivan W, Windsor DM, Werren

565 JH. 2008. Wolbachia modification of sperm does not always require residence within developing 566 sperm. Heredity 101: 420-428. DOI: 10.1038/hdy.2008.71.

567 Clark TL, Meinke LJ, Skoda SR, Foster JE. 2001. Occurrence of Wolbachia in Selected 568 Diabroticite (Coleoptera: Chrysomelidae) Beetles. Annals of the Entomological Society of 569 America 94:877-885. 
570 Cordaux R, Bouchon D, Greve P. 2011. The impact of endosymbionts on the evolution of host

571 sex-determination mechanisms. Trends in Genetics 27:332-341. DOI 10.1016/j.tig.2011.05.002

572 Czarnetzki AB, Tebbe CC. 2004. Detection and phylogenetic analysis of Wolbachia in

573 Collembola. Environmental Microbiology 6:35-44. DOI 10.1046/j.1462-2920.2003.00537.x.

574 DeLay B, Mamidala P, Wijeratne A, Wijeratne S, Mittapalli O, Wang J, Lamp W. 2012.

575 Transcriptome analysis of the salivary glands of potato leafhopper, Empoasca fabae. Journal of

576 Insect Physiology 58:1626-1634. DOI 10.1016/j.jinsphys.2012.10.002.

577 Dudek K, Humińska K, Wojciechowicz J, Tryjanowski P. 2017. Metagenomic survey of 578 bacteria associated with the invasive ladybird Harmonia axyridis (Coleoptera: Coccinellidae).

579 European Journal of Entomology 114:312-316. DOI 10.14411/eje.2017.038.

580 Dunning Hotopp J C, Clark ME, Oliveira DCSG, Foster JM, Fischer P, Muñoz Torres MC, 581 Giebel JD, Kumar N, Ishmael N, Wang S, Ingram J, Nene RV, Shepard J, Tomkins J, 582 Richards S, Spiro DJ, Ghedin E, Slatko BE, Tettelin H, Werren JH. 2007. Widespread lateral 583 gene transfer from intracellular bacteria to multicellular eukaryotes. Science (New York, N.Y.), 584 317: 1753-1756. DOI:10.1126/science.1142490

585 Duron O, Bouchon D, Boutin S, Bellamy L, Zhou LQ, Engelstadter J, Hurst GD. 2008. The 586 diversity of reproductive parasites among arthropods: Wolbachia do not walk alone. BMC 587 Biology 6:27. DOI 10.1186/1741-7007-6-27.

588 Elnagdy S, Majerus MEN, Gardener M, Lawson-Handley L. 2013. The direct effects of male589 killer infection on fitness of ladybird hosts (Coleoptera: Coccinellidae). Journal of Evolutionary 590 Biology 26:1816-1825. DOI 10.1111/jeb.12186.

591 Farrell BD. 1998. "Inordinate fondness" explained: why are there so many beetles? Science 592 281:555-559. DOI 10.1126/science.281.5376.555.

593 Fialho RF, Stevens L. 2000. Male-killing Wolbachia in a flour beetle. Proceedings of the Royal 594 Society B: Biological Sciences 267:1469-1474. DOI 10.1098/rspb.2000.1166.

595 Fialho RF, Stevens L. 1996. Wolbachia infections in the flour beetle Tribolium 596 confusum: evidence for a common incompatibility type across strains. Journal of Invertebrate 597 Pathology 67:195-197. DOI 10.1006/jipa.1996.0032,

598 Fialho RF, Stevens L. 1997. Molecular evidence for single Wolbachia infections among 599 geographic strains of the flour beetle Tribolium confusum. Proceedings of the Royal Society B:

600 Biological Sciences 264:1065-1068. DOI 10.1098/rspb.1997.0147.

601 Floate KD, Coghlin PC, Dosdall L. 2011. A Test using Wolbachia Bacteria to Identify Eurasian 602 Source Populations of Cabbage Seedpod Weevil, Ceutorhynchus obstrictus (Marsham), in North 603 America. Environmental Entomology 40:818-823. DOI 10.1603/EN10315

604 Frank JH, Erwin TL \& Hemenway RC. 2009. Economically Beneficial Ground Beetles. The 605 specialized predators Pheropsophus aequinoctialis (L.) and Stenaptinus jessoensis (Morawitz): 606 Their laboratory behavior and descriptions of immature stages (Coleoptera, Carabidae, 607 Brachininae). Zookeys 14: 1-36. DOI: 10.3897/zookeys.14.188. 
608 Funkhouser-Jones LJ, Sehnert SR, Martínez-Rodríguez P, Toribio-Fernández R, Pita M,

609 Bella JL, Bordenstein SR. 2015. Wolbachia co-infection in a hybrid zone: discovery of

610 horizontal gene transfers from two Wolbachia supergroups into an animal genome. PeerJ 3:

611 e1479. DOI:10.7717/peerj.1479

612 García-Vázquez D, Ribera I. 2016. The origin of widespread species in a poor dispersing

613 lineage (diving beetle genus Deronectes). PeerJ 4: e2514. DOI: 10.7717/peerj.2514.

614 Giordano R, Jackson JJ, Robertson HM. 1997. The role of Wolbachia bacteria in reproductive

615 incompatibilities and hybrid zones of Diabrotica beetles and Gryllus crickets. Proceedings of the

616 National Academy of Sciences of the USA 94:11439-11444.

617 Goodacre SL, Fricke C, Martin OY. 2015. A screen for bacterial endosymbionts in the model

618 organisms Tribolium castaneum, T.confusum, Callosobruchus maculatus, and related species.

619 Insect Science 22: 165-177. DOI: 10.1111/1744-7917.12096.

620 Goodacre SL, Martin OY, Thomas CFG, Hewitt GM. 2006. Wolbachia and other

621 endosymbiont infections in spiders. Molecular Ecology 15:517-527. DOI 10.1111/j.1365-

622 294X.2005.02802.x.

623 Goryachevaa II, Blekhmanb AV, Andrianova BV, Gorelovaa TV, Zakharova IA. 2015.

624 Genotypic Diversity of Wolbachia pipientis in Native and Invasive Harmonia axyridis Pall., 1773

625 (Coleoptera, Coccinellidae) Populations. Russian Journal of Genetics 8:731-736.

626 Goto S, Anbutsu H, Fukatsu T. 2006. Asymmetrical interactions between Wolbachia and

627 Spiroplasma endosymbionts coexisting in the same insect host. Applied and Environmental

628 Microbiology 72:4805-4810. DOI 10.1128/AEM.00416-06.

629 Guindon S, Dufayard JF, Lefort V, Anisimova M, Hordijk W, Gascuel O. 2010. New

630 algorithms and methods to estimate maximum-likelihood phylogenies: assessing the performance

631 of PhyML 3.0. Systematic Biology 59:307-321. DOI 10.1093/sysbio/syq010.

632 Hartelt K, Oehme R, Frank H, Brockmann SO, Hassler D, Kimmig P. 2004. Pathogens and

633 symbionts in ticks: prevalence of Anaplasma phagocytophilum (Ehrlichia sp.), Wolbachia sp.,

634 Rickettsia sp., and Babesia sp. in Southern Germany. International Journal of Medical

635 Microbiology Supplements 293:86-92. DOI 10.1016/S1433-1128(04)80013-5.

636 Heddi A, Grenier AM, Khatchadourian Ch, Charles H, Nardon P. 1999. Four intracellular

637 genomes direct weevil biology: Nuclear, mitochondrial, principal endosymbiont, and Wolbachia.

638 Proceedings of the National Academy of Sciences of the USA 96:6814-6819. DOI

$63910.1073 /$ pnas.96.12.6814.

640 Heintzman PD, Elias SA, Moore K, Paszkiewicz K, Barnes I. 2014. Characterizing DNA

641 preservation in degraded specimens of Amara alpina (Carabidae: Coleoptera). Molecular

642 Ecology Resources 14:606-615. DOI 10.1111/1755-0998.12205.

643 Hilgenboecker K, Hammerstein P, Schlattmann P, Telschow A, Werren JH. 2008. How many

644 species are infected with Wolbachia? A statistical analysis of current data. FEMS Microbiology

645 Letters 281:215-220. DOI 10.1111/j.1574-6968.2008.01110.x. 
646 Huigens ME, Almeida RP de, Boons P a H, Luck RF, Stouthamer R. 2004. Natural

647 interspecific and intraspecific horizontal transfer of parthenogenesis-inducing Wolbachia in

648 Trichogramma wasps. Proceedings of the Royal Society B: Biological Sciences 271:509-515.

649 DOI 10.1098/rspb.2003.2640

650 Hurst GDD, Bandi C, Sacchi L, Cochrane A, Bertrand D, Karaca I, Majerus MEN.1999.

651 Adonia variegata (Coleoptera: Coccinellidae) bears maternally inherited Flavobacteria that kill 652 males only. Parasitology 118:125-134.

653 Hurst GDD, Jiggins FM. 2005. Problems with mitochondrial DNA as a marker in population, 654 phylogeographic and phylogenetic studies : the effects of inherited symbionts. Proceedings of the 655 National Academy of Sciences USA 272:1525-1534. DOI 10.1098/rspb.2005.3056

656 Hurst GDD, Jiggins FM, von der Schulenburg JHG, Bertrand D, West SA, Goriacheva II, 657 Zakharov IA, Werren JH, Stouthamer R, Majerus MEN. 1999b. Male-killing Wolbachia in 658 two species of insect. Proceedings of the Royal Society B: Biological Sciences 266: 735-740.

659 DOI 10.1098/rspb.1999.0698.

660 Iwase S, Tani S, Saeki Y, Tuda M, Haran J, Skuhrovec J, Takagi M. 2015. Dynamics of 661 infection with Wolbachia in Hyperapostica (Coleoptera: Curculionidae) during invasion and 662 establishment. Biological Invasions 17: 3639-3648. DOI: 10.1007/s10530-015-0985-1.

663 Jäckel R, Mora D, Dobler S. 2013. Evidence for selective sweeps by Wolbachia infections: 664 Phylogeny of Altica leaf beetles and their reproductive parasites. Molecular Ecology 22: 4241665 4255. DOI 10.1111/mec.12389.

666 Jeyaprakash A, Hoy MA 2000. Long PCR improves Wolbachia DNA amplification: wsp 667 sequences found in 76\% of 63 arthropod species. Insect Molecular Biology 9: 393-405. DOI 668 10.1046/j.1365-2583.2000.00203.x.

669 Jeong G, Kang T, Park H, Choi J, Hwang S, Kim W, Choi Y, Lee K, Park I, Sim H 2009. 670 Wolbachia infection in the Korean endemic firefly, Luciola unmunsana (Coleoptera:

671 Lampyridae). Journal of Asia-Pacific Entomology 12:33-36. DOI 10.1016/j.aspen.2008.11.001.

672 Kageyama D, Narita S, Imamura T, Miyanoshita A. 2010. Detection and identification of 673 Wolbachia endosymbionts from laboratory stocks of stored-product insect pests and their 674 parasitoids. Journal of Stored Products Research 46: 13-19. DOI: 10.1016/j.jspr.2009.07.003.

675 Kajtoch L, Montagna M, Wanat M. 2017. Species delimitation within the 676 Bothryorrhynchapion weevils: multiple evidence from genetics, morphology and ecological 677 associations. Molecular Phylogenetics and Evolution. DOI: 10.1016/j.ympev.2017.12.022.

678 Kajtoch L, Korotyaev B, Lachowska-Cierlik D. 2012. Genetic distinctness of parthenogenetic 679 forms of European Polydrusus weevils of the subgenus Scythodrusus. Insect Science 19:183680 194. DOI 10.1111/j.1744-7917.2011.01448.x.

681 Kawasaki Y, Schuler H, Stauffer C, Lakatos F, Kajimura H. 2016. Wolbachia endosymbionts 682 in haplodiploid and diploid scolytine beetles (Coleoptera: Curculionidae:

683 Scolytinae). Environmental Microbiology Reports 8:680-688. DOI 10.1111/1758-2229.12425. 
684 Kawasaki Y, Ito M, Miura K, Kajimura H. 2010. Superinfection of five Wolbachia in the alnus 685 ambrosia beetle, Xylosandrus germanus (Blandford) (Coleoptera: Curuculionidae). Bullettin of 686 Entomological Research 100:231-239. DOI 10.1017/S000748530999023X.

687 Keller GP, Windsor DM, Scucedo JM, Werren JH. 2004. Reproductive effects and 688 geographical distributions of two Wolbachia strains infecting the Neotropical 689 beetle, Chelymorpha alternans Boh. (Chrysomelidae, Cassidinae). Molecular Ecology 13:2405690 2420. DOI 10.1111/j.1365-294X.2004.02213.x.

691 Kikuchi Y, Fukatsu T. 2003. Diversity of Wolbachia endosymbionts in heteropteran bugs.

692 Applied and Environmental Microbiology 69:6082-6090. DOI 10.1128/AEM.69.10.6082-

6936090.2003

694 Kittayapong P, Jamnongluk W, Thipaksorn A, Milne JR, Sindhusake C. 2003. Wolbachia 695 infection complexity among insects in the tropical rice-field community. Molecular Ecology 12: 696 1049-1060. DOI:10.1046/j.1365-294X.2003.01793.x

697 Kolasa M, Montagna M, Mereghetti V, Kubisz D, Mazur MA, Kajtoch L. 2017. Preliminary 698 evidence of Wolbachia horizontal transmission between Crioceris leaf beetles 699 and Asparagus host plants. European Journal of Entomology 114:446-454. DOI 700 10.14411/eje.2017.057

701 Kondo N, Ijichi N, Shimada M, Fukatsu T. 2002. Prevailing triple infection 702 with Wolbachia in Callosobruchus chinensis (Coleoptera: Bruchidae). Molecular 703 Ecology 11:167-180. DOI 10.1046/j.0962-1083.2001.01432.x

704 Kondo N, Shimada M, Fukatsu T. 1999. High prevalence of Wolbachia in the azuki bean 705 beetle Callosobruchus chinensis (Coleoptera, Bruchidae). Zoological Science 16:955-962. DOI $706 \quad 10.2108 /$ zsj.16.955

707 Kondo N, Shimada M, Fukatsu T. 2005. Infection density of Wolbachia endosymbiont affected 708 by co-infection and host genotype. Biology Letters 1:488-491. DOI 10.1098/rsb1.2005.0340

709 Kondo N, Tuda M, Toquenaga Y, Lan YC, Buranapanichpan S, Horng SB, Shimada M, 710 Fukatsu T. 2011. Wolbachia infections in world populations of bean beetles (Coleoptera: 711 Chrysomelidae: Bruchinae) infesting cultivated and wild legumes. Zoological Science 28:501712 508. DOI 10.2108/zsj.28.501

713 Koutsovoulos G, Makepeace B, Tanya VN, Blaxter M. 2014. Palaeosymbiosis Revealed by 714 Genomic Fossils of Wolbachia in a Strongyloidean Nematode. PLOS Genetics: 10(6), e1004397. 715 doi:10.1371/journal.pgen.1004397

716 Kubisz D, Kajtoch Ł, Mazur MA, Lis A, Holecová M. 2012. Conservation genetics of highly 717 isolated populations of xerothermic Crioceris quatuordecimpunctata (Coleoptera:

718 Chrysomelidae). Invertebrate Biology 131:333-344. DOI 10.1111/j.1744-7410.2012.00276.x.

719 Lachowska-Cierlik D, Kajtoch $\mathbf{L}$, Knutelski S. 2010. Occurrence of Wolbachia in central

720 European weevils: correlations with host systematics, ecology and biology. Entomologia

721 Experimentalis et Applicata 14:105-118. DOI 10.1111/j.1570-7458.2010.00974.x. 
722 Lawson ET, Mousseau TA, Klaper R, Hunter MD, Werren JH. 2001. Rickettsia associated

723 with male-killing in a buprestid beetle. Heredity 86:497-505. DOI 10.1046/j.1365-

724 2540.2001.00848.x.

725 Li YY, Fields PG, Pang B, Coghlin PC, Floate KD. 2015. Prevalence and diversity of

726 Wolbachia bacteria infecting insect pests of stored products. Journal of Stored Products Research

727 62: 93-100. DOI: 10.1016/j.jspr.2009.07.003.

728 Li YY, Fields PG, Pang BP, Floate KD. 2016. Effects of tetracycline and rifampicin treatmens

729 on the fecundity of the Wolbachia-infected host, Tribolium confusum (Coleoptera:

730 Tenebrionidae). Journal of Economic Entomology 109:1458-1464. DOI 10.1093/jee/tow067.

731 Li SJ, Ahmed MZ, Lv N, Shi PQ, Wang XM, Huang JL, Qiu BL. 2016. Plant-mediated

732 horizontal transmission of Wolbachia between whiteflies. The ISME Journal 11:1019-1028. DOI

$733 \quad 10.1038 /$ ismej.2016.164

734 Lindsey AR, Bordenstein SR, Newton IL, Rasgon JL. 2016. Wolbachia pipientis should not be

735 split into multiple species: A response to Ramírez-Puebla et al.,, "Species in Wolbachia? Proposal

736 for the designation of 'Candidatus Wolbachia bourtzisii', 'Candidatus Wolbachia

737 onchocercicola', 'Candidatus Wolbachia blaxteri', 'Candidatus Wolbachia brugii', 'Candidatus

738 Wolbachia taylori' 'Candidatus Wolbachia collembolicola' and 'Candidatus Wolbachia

739 multihospitum' for the different species within Wolbachia supergroups". Systematic and Applied

740 Microbiology 39:220-222. DOI 10.1016/j.syapm.2016.03.001.

741 Lu F, Kang XY, Lorenz G, Espino L, Jiang MX, Way MO 2014. Culture-independent analysis

742 of bacterial communities in the gut of rice water weevil (Coleoptera: Curculionidae). Annals of

743 the Entomological Society of America 10,592-600. DOI 10.1603/AN13145.

744

745

746

747

748

749

750

751

752

753

754

755

756

757

758

759
Majerus TMO, Majerus MEN, Knowles B, Wheeler J, Bertrand D, Kuznetsov VN, Ueno H, Hurst GDD. 1998. Extreme variation in the prevalence of inherited male-killing microorganisms between three populations of Harmonia axyridis (Coleoptera: Coccinellidae). Heredity 81:683691. DOI 10.1046/j.1365-2540.1998.00438.x.

Majerus MEN, Majerus TMO. 2000. Multiple causes of male-killing in a single sample of the 2-spot ladybird, Adalia bipunctata (Coleoptera:Coccinellidae) from Moscow. Heredity 84, 605-609. DOI 10.1046/j.1365-2540.2000.00710.x

Malloch G, Fenton B, Butcher RD. 2000. Molecular evidence for multiple infections of a new subgroup of Wolbachia in the European raspberry beetle Byturus tomentosus. Molecular Ecology 9:77-90.

Mariño Y, Verle Rodrigues JC, Bayman P. 2017. Wolbachia Affects Reproduction and Population Dynamics of the Coffee Berry Borer (Hypothenemus hampei): Implications for Biological Control Insects 8:8. DOI 10.3390/insects8010008.

Mazur M.A., Holecová M., Lachowska-Cierlik D., Lis A., Kubisz D., Kajtoch L. 2016. Selective sweep of Wolbachia and parthenogenetic host genomes on the example of the weevil Eusomus ovulum. Insect Molecular Biology 25:701-711. DOI 10.1111/imb.1225. 
760

761

762

763

764

765

766

767

768

769

770

771

772

773

774

775

776

777

778

779

780

781

782

783

784

785

786

787

788

789

790

791

792

793

794

795

796

797

Mazur MA, Kubisz D, Kajtoch L. 2014. Restricted geographic distribution and low genetic distinctiveness of steppic Crioceris quinquepunctata (Coleoptera: Chrysomelidae) populations in central-east Europe. Entomologica Fennica 25:103-111.

Ming QL, Shen JF, Cheng C., Liu CM, Feng ZJ. 2015. Wolbachia infection dynamics in Tribolium confusum (Coleoptera: Tenebrionidae) and their effects on host mating behavior and reproduction. Journal of Economic Entomology 108:1408-1415. DOI 10.1093/jee/tov053.

Minh BQ, Nguyen NAT, von Haeseler A. 2013. Ultrafast Approximation for Phylogenetic Bootstrap. Molecular Biology and Evolution 30:1188-1195. DOI 10.1093/molbev/mst024.

Moher D, Liberati A, Tetzlaff J, Altman DG. 2009. Preferred reporting items for systematic reviews and meta-analyses: the PRISMA statement. Annals of Internal Medicine 151:264-269 DOI 10.7326/0003-4819-151-4-200908180-00135.

Montagna M, Chouaia B, Sacchi L, Porretta D, Martin E, Giorgi A, Lozzia GC, Epis SA. 2014. New Strain of Wolbachia in an Alpine Population of the Viviparous Oreina cacaliae (Coleoptera: Chrysomelidae). Environmental Entomology 43:913-922. DOI 10.1603/EN13228.

Nikoh N, Tanaka K, Shibata F, Kondo N, Hizume M, Shimada M, Fukatsu T. 2008. Wolbachia genome integrated in an insect chromosome: evolution and fate of laterally transferred endosymbiont genes. Genome Research 18:272-280. DOI 10.1101/gr.7144908.

Nirgianaki A, Banks GK, Frohlich DR, Veneti Z, Braig HR, Miller TA, Bedford ID, Markham PG, Savakis C, Bourtzis K 2003. Wolbachia Infections of the Whitefly Bemisia tabaci. Current Microbiology 47: 0093-0101. DOI:10.1007/s00284-002-3969-1

Numajiri Y, Kondo NI, Toquenaga Y. 2017. Melanic mutation causes a fitness decline in bean beetles infected by Wolbachia. Entomologia Experimentalis et Applicata 164: 54-65. DOI: 10.1111/eea.12588.

O’Neill SL, Giordano R, Colbert AM, Karr TL, Robertson HM. 1992. 16S rRNA phylogenetic analysis of the bacterial endosymbionts associated with cytoplasmic incompatibity in insects. Proceedings of National Academy of Sciences of the USA 89:2699-2702.

Okayama K, Katsuki M, Sumida Y, Okada K. 2016. Costs and benefits of symbiosis between a bean beetle and Wolbachia. Animal Behaviour 119:19-26. DOI 10.1016/j.anbehav.2016.07.004.

O'Neill SL. 2007. Wolbachia-host interactions: connecting phenotype to genotype. Current Opinion in Microbiology 10:221-224. DOI 10.1016/j.mib.2007.05.002.

Pankewitz F, Zöllmer A, Hilker M, Gräser Y. 2007. Presence of Wolbachia in Insect Eggs Containing Antimicrobially Active Anthraquinones. Microbial Ecology 54: 713-721. DOI: 10.1007/s00248-007-9230-5.

Perotti MA, Young DK, Braig HR. 2016. The ghost sex-life of the paedogenetic beetle Micromalthus debilis. Scientific reports 6: 27364 . DOI: 10.1038/srep27364.

Piper RW, Compton SG, Rasplus JY, Piry S. 2001. The species status of Cathormiocerus britannicus, an endemic, endangered British weevil. Biological Conservation 101:9-13. DOI 10.1016/S0006-3207(01)00048-9 
798 Pourali P, Roayaei Ardakani M, Jolodar A, Razi Jalali MH. 2009. PCR screening of the

799 Wolbachia in some arthropods and nematodes in Khuzestan province. Iranian Journal of

800 Veterinary Research 10:216-222.

801 Prakash BM \& Puttaraju HP. 2006. Wolbachia endosymbiont in some insect pests of 802 sericulture. Current Science 90: 1671-1674.

803 Ramirez-Puebla ST, Servin-Garciduenas LE, Ormeno-Orrillo E, Vera-Ponce de Leon A, 804 Rosenblueth M, Delaye L, Martinez J, Martinez-Romero E. 2015. Species in Wolbachia?

805 Proposal for the designation of 'Candidatus Wolbachia bourtzisii', 'Candidatus Wolbachia 806 onchocercicola', 'Candidatus Wolbachia blaxteri', 'Candidatus Wolbachia brugii', 'Candidatus

807 Wolbachia taylori' 'Candidatus Wolbachia collembolicola' and 'Candidatus Wolbachia 808 multihospitum' for the different species within Wolbachia supergroups. Systematic and Applied 809 Microbiology 38:390-399. DOI 10.1016/j.syapm.2015.05.005.

810 Rodriguero MS, Confalonieri VA, Guedes JVC, Lanteri AA. 2010a. Wolbachia infection in 811 the tribe Naupactini (Coleoptera, Curculionidae): association between thelytokous

812 parthenogenesis and infection status. Insect Molecular Biology 19:631-640. DOI 10.1111/j.1365813 2583.2010.01018.x.

814 Rodriguero MS, Lanteri AA, Confalonieri VA. 2010b. Mito-nuclear genetic comparison in a 815 Wolbachia infected weevil: insights on reproductive mode, infection age and evolutionary forces 816 shaping genetic variation. BMC Evolutionary Biology 10:340. DOI 10.1186/1471-2148-10-340.

817 Roehrdanz R, Levine E 2007. Wolbachia bacterial infections linked to mitochondrial DNA 818 reproductive isolation among populations of northern corn rootworm (Coleoptera: 819 Chrysomelidae). Annals of the Entomological Society of America 100:522-531. DOI 820 10.1603/0013-8746(2007)100[522:WBILTM]2.0.CO;2.

821 Roehrdanz R, Olson D, Bourchier R, Sears S, Cortilet A, Fauske G 2006. Mitochondrial 822 DNA diversity and Wolbachia infection in the flea beetle Aphthona nigriscutis (Coleoptera:

823 Chrysomelidae): an introduced biocontrol agent for leafy spurge. Biological Control 37:1-8. DOI 824 10.1016/j.biocontrol.2005.12.004.

825 Roehrdanz RL, Wichmann SGS. 2013. Wolbachia wsp gene clones detect the distribution of 826 Wolbachia variants and wsp hypervariable regions among 160 individuals of a multistrain 827 infected population of Diabrotica barberi (Coleoptera: Chrysomelidae). Annals of the 828 Entomological Society of America 106:329-338. DOI 10.1603/AN12118.

829 Roehrdanz R, Olson D, Bourchier R, Sears S, Cortilet A, Fauske G. 2006. Mitochondrial 830 DNA diversity and Wolbachia infection in the flea beetle Aphthona nigriscutis (Coleoptera : 831 Chrysomelidae): An introduced biocontrol agent for leafy spurge. Biological Control 37:1-8. 832 DOI 10.1016/j.biocontrol.2005.12.004.

833 Russell JA. 2012. The ants (Hymenoptera: Formicidae) are unique and enigmatic hosts of 834 prevalent Wolbachia (Alphaproteobacteria) symbionts. Myrmecological News 16: 7-23.

835 Schneider DI, Riegler M, Arthofer W, Merçot H, Stauffer C, Miller WJ. 2013. Uncovering 836 Wolbachia diversity upon artificial host transfer. PLoS ONE 8:e82402. 
837 Schuler H, Bertheau C, Egan SP, Feder JL, Riegler M, Schlick-Steiner BC, Steiner FM, 838 Johannesen J, Kern P, Tuba K, Lakatos F, Köppler K, Arthofer W, Stauffer C. 2013.

839 Evidence for a recent horizontal transmission and spatial spread of Wolbachia from endemic

840 Rhagoletis cerasi (Diptera: Tephritidae) to invasive Rhagoletis cingulata in Europe. Molecular

841 Ecology 22:4101-4111.

842 Sharaf K, Hadid Y, Pavliček T, Nevo E. 2013. Local genetic population divergence in a saw843 toothed grain beetle, Oryzaephilus surinamensis (L.) (Coleoptera, Cucujidae). Journal of Stored 844 Products Research 53:72-76.

845 Sharaf K, Horovă L, Pavliček T, Nevo E, Bureš P. 2010. Genome size and base composition 846 in Oryzaephilius surinamensis (Coleoptera: Sylvanidae) (Cikeiotera: Sylvanidae) and differences 847 between native (feral) and silo pest populations in Israel. Journal of Stored Products Research 848 46:34-37.

849 Shoemaker DD, Machado CA, Molbo D, Werren JH, Windsor DM, Herre EA. 2002. The 850 distribution of Wolbachia in fig wasps: correlations with host phylogeny, ecology and population 851 structure. Proceedings of the Royal Society of London B: Biological Sciences 269:2257-2267. 852 DOI 10.1098/rspb.2002.2100.

853 Sintupachee S, Milne JR, Poonchaisri S, Baimai V, Kittayapong P. 2006. Closely Related 854 Wolbachia Strains within the Pumpkin Arthropod Community and the Potential for Horizontal 855 Transmission via the Plant. Microbial Ecology 51: 294-301. DOI:10.1007/s00248-006-9036-X

856 Smith MA, Bertrand C, Crosby K, Eveleigh ES, Fernandez-Triana J, Fisher BL, Gibbs J, 857 Hajibabaei M, Hallwachs W, Hind K, Hrcek J, Huang DW, Janda M, Janzen DH, Li Y, 858 Miller SE, Packer L, Quicke D, Ratnasingham S, Rodriguez J, Rougerie R, Shaw MR, 859 Sheffield C, Stahlhut JK, Steinke D, Whitfield J, Wood M, Zhou X. 2012. Wolbachia and 860 DNA Barcoding Insects: Patterns, Potential, and Problems. PLoS ONE 7:e36514. DOI 861 10.1371/journal.pone.0036514.

862 Son Y, Luckhart S, Zhang X, Lieber MJ, Lewis EE. 2008. Effects and implications of 863 antibiotic treatment on Wolbachia - infected vine weevil (Coleoptera: Curculionidae).

864 Agricultural and Forest Entomology 10:147-155. DOI 10.1111/j.1461-9563.2008.00369.x.

865 Sontowski R, Bernhard D, Bleidorn C, Schlegel M, Gerth M. 2015. Wolbachia distribution in 866 selected beetle taxa characterized by PCR screens and MLST data. Ecology and Evolution 867 5:4345-4353. DOI 10.1002/ece3.1641.

868 Stahlhut JK, Desjardins CA, Clark ME, Baldo L, Russell JA, Werren JH, Jaenike J. 2010. 869 The mushroom habitat as an ecological arena for global exchange of Wolbachia. Molecular 870 Ecology 19:1940-1952. DOI 10.1111/j.1365-294X.2010.04572.x.

871 Stenberg, P., Lundmark, M., 2004. Distribution, mechanisms and evolutionary significance of 872 clonality and polyploidy in weevils. Agricultural and Forest Entomology 6:259-266. DOI 873 10.1111/j.1461-9555.2004.00231.x.

874 Stouthamer R, Breeuwer JAJ, Hurst GDD 1999. Wolbachia pipientis: microbial manipulator 875 of arthropod reproduction. Annual Review of Microbiology 53:71-102. DOI

876 10.1146/annurev.micro.53.1.71. 
877 Tagami Y, Miura K. 2004. Distribution and prevalence of Wolbachia in Japanese populations of

878 Lepidoptera. Insect Molecular Biology 13:359-364. DOI 10.1111/j.0962-1075.2004.00492.x.

879 Takano SI, Tuda M, Takasu K, Furuya N, Imamura Y, Kim S, Tashiro K, Iiyama K, Tavares

880 M, Amaral AC. 2017. Unique clade of alphaproteobacterial endosymbionts induces complete

881 cytoplasmic incompatibility in the coconut beetle. Proceedins of National Academy of Sciences

882 USA 114: 6110-6115. DOI: 10.1073/pnas.1618094114.

883 Taylor MJ, Hoerauf A. 1999. Wolbachia bacteria of filarial nematodes. Parasitology Today

884 15:437-442. DOI 10.1016/S0169-4758(99)01533-1.

885 Tinsley MC, Majerus MEN. 2006. A new male-killing parasitism: Spiroplasma bacteria infect

886 the ladybird beetle Anisosticta novemdecimpunctata (Coleoptera: Coccinellidae). Parasitology

887 132:757-765. DOI: 10.1017/S0031182005009789.

888 Toju H, Fukatsu T. 2011. Diversity and infection prevalence of endosymbionts in natural 889 populations of the chestnut weevil: Relevance of local climate and host plants. Molecular 890 Ecology 20: 853-868. DOI: 10.1111/j.1365-294X.2010.04980.x.

891 Toju H, Tanabe AS, Notsu Y, Sota T, Fukatsu T. 2013. Diversification of endosymbiosis: 892 replacements, co-speciation and promiscuity of bacteriocyte symbionts in weevils. The ISME 893 Journal 7: 1378-1390. DOI: 10.1038/ismej.2013.27.

894 Toševski I, Caldara R, Jović J, Hernández-Vera G, Baviera C, Gassman A, Emerson BC. 895 2015. Host associated genetic divergence and taxonomy in the Rhinusa pilosa Gyllenhal species 896 complex: an integrative approach. Systematic Entomology 40: 268-287. DOI:

897 10.1111/syen.12109.

898 Trifinopoulos J, Nguyen LT, von Haeseler A, Minh BQ. 2016. W-IQ-TREE: a fast online 899 phylogenetic tool for maximum likelihood analysis. Nucleic Acids Research 44:W232-W235.

900 DOI 10.1093/nar/gkw256.

901 Vega FE, Benavides P, Stuart J, O'Neill SL. 2002. Wolbachia infection in the coffee berry 902 borer (Coleoptera: Scolytidae). Annals of the Entomological Society of America 95:374-378. DOI 903 10.1603/0013-8746(2002)095[0374:WIITCB]2.0.CO;2.

904 Weeks AR, Reynolds KT, Hoffmann AA 2002. Wolbachia dynamics and host effects: What has 905 (and has not) been demonstrated? Trends of Ecology \& Evolution 17:257-262. DOI 906 10.1016/S0169-5347(02)02480-1.

907 Weinert LA, Tinsley MC, Temperley M, Jiggins FM. 2007. Are we underestimating the 908 diversity and incidence of insect bacterial symbionts? A case study in ladybird beetles. Biology 909 Letters 3: 678-681. DOI: 10.1098/rsbl.2007.0373.

910 Weinert LA, Araujo-Jnr EV, Ahmed MZ, Welch JJ. 2015. The incidence. of bacterial 911 endosymbionts in terrestrial. arthropods. Proceedings of the Royal Society B: Biological Science 912 282: 20150249. DOI: 10.1098/rspb.2015.0249

913 Werren JH, Hurst GDD, Zhang W, Breeuwer JA, Stouthamer R, Majerus ME. 1994. 914 Rickettsial relative associated with male killing in the ladybird beetle (Adalia bipunctata).

915 Journal Bacteriology 176:388-394. DOI 10.1128/jb.176.2.388-394.1994. 
916 Werren JH, Windsor D, Guo L 1995. Distribution of Wolbachia among neotropical arthropods.

917 Proceedings of the Royal Society B: Biological Sciences 262:197-204. DOI

$91810.1098 / \mathrm{rspb} .1995 .0196$.

919 Werren, JH, O'Neill, SL. 1997. The evolution of heritable symbionts. In: O'Neill SL, Hoffmann 920 AA, Werren, JH, eds). Influential Passengers: Inherited Microorganisms and Arthropod

921 Reproduction. Oxford:Oxford University Press, 1-41.

922 Werren JH. 1997. Biology of Wolbachia. Annual Review of Entomology 42:587-609. DIO

923 10.1146/annurev.ento.42.1.587.

924 White JA, Richards NK, Laugraud A, Saeed A, Curry MM, McNeill MR. 2015.

925 Endosymbiotic candidates for parasitoid defense in exotic and native New Zealand weevils.

926 Microbial Ecology 70: 274-286. DOI: 10.1007/s00248-014-0561-8.

927 Xue H-J, Li W-Z, Nie R-E, Yang X-K. 2011. Recent Speciation in Three Closely Related 928 Sympatric Specialists: Inferences Using Multi-Locus Sequence, Post-Mating Isolation and 929 Endosymbiont Data. PLoS ONE 6: e27834. DOI:10.1371/journal.pone.0027834.

930 Yun Y, Peng Y, Liu FX, Lei C. 2011. Wolbachia screening in spiders and assessment of 931 horizontal transmission between predator and prey. Neotropical Entomology 40:164-169. DOI 932 10.1590/S1519-566X2011000200002.

933 Zchori-Fein E, Borad C, Harari AR. 2006. Oogenesis in the date stone beetle, 934 Coccotrypesdactyliperda, depends on symbiotic bacteria. Physiological Entomology 31: 164935 169. DOI: 10.1111/j.1365-3032.2006.00504.x.

936 Zchori-Fein E, Perlman SJ. 2004. Distribution of the bacterial symbiont Cardinium in 937 arthropods. Molecular Ecology 13:2009-2016. DOI 10.1111/j.1365-294X.2004.02203.x.

938 Zhang X, Luckhart S, Tu J, Pfeiffer DG. 2010. Analysis of Wolbachia strains associated with 939 Conotrachelus nenuphar (Coleoptera: Curculionidae) in the eastern United States. Environmental 940 Entomology 39:396-405. DOI 10.1603/EN09276.

941 Zug R, Hammerstein P. 2012. Still a host of hosts for Wolbachia: analysis of recent data 942 suggests that $40 \%$ of terrestrial arthropod species are infected. PLoS One 7:e38544. DOI 943 10.1371/journal.pone.0038544. 


\section{Table $\mathbf{1}$ (on next page)}

Share of Wolbachia infected species among families and genera of examined beetles.

Only taxonomic groups for which at least two species were tested are presented. 


\begin{tabular}{|c|c|c|c|c|c|c|c|c|}
\hline family & $\mathrm{N}$ of examined & $\%$ of infected & genus & $\mathrm{N}$ of examined & $\%$ of infected & genus & $\mathrm{N}$ of examined & $\%$ of infected \\
\hline Buprestidae & 61 & 23.0 & Barypeithes & 9 & 11.0 & Julodis & 2 & 0.0 \\
\hline Chrysomelidae & 84 & 45.2 & Brachysomus & 4 & 0.0 & Koreoculio & 2 & 50.0 \\
\hline Curculionidae & 137 & 41.6 & Brumoides & 2 & 0.0 & Laccophilus & 2 & 0.0 \\
\hline Dytiscidae & 36 & 16.7 & Buprestis & 3 & 0.0 & Limnebius & 7 & 28.6 \\
\hline Gyrinidae & 3 & 33.3 & Byturus & 3 & 33.0 & Longitarsus & 3 & 100.0 \\
\hline Haliplidae & 2 & 50.0 & Callosbruchus & 3 & 33.3 & Meliboeus & 2 & 0.0 \\
\hline Hydraenidae & 27 & 63.0 & Callosobruchus & 7 & 33.0 & Micraspis & 2 & 0.0 \\
\hline Hydrophilidae & 12 & 16.7 & Capnodis & 3 & 33.3 & Naupactus & 16 & 69.0 \\
\hline Noteridae & 2 & 100.0 & Charidotella & 2 & 50.0 & Neoglanis & 2 & 0.0 \\
\hline Tenebrionidae & 11 & 9.1 & Chlaenius & 7 & 14.3 & Ochthebius & 12 & 41.7 \\
\hline subfamily & $\mathrm{N}$ of examined & $\%$ of infected & Chrysobothris & 3 & 33.3 & Ophionea & 3 & 0.0 \\
\hline Bruchinae & 24 & 16.7 & Coccinella & 2 & 50.0 & Oreina & 5 & 80.0 \\
\hline Galerucinae & 12 & 25.0 & Crioceris & 5 & 40.0 & Otiorhynchus & 4 & 50.0 \\
\hline Curculionidae & 36 & 16.7 & Curculio & 23 & 17.4 & Paederus & 3 & 0.0 \\
\hline Scolytinae & 23 & 34.8 & Cyanapion & 6 & 50.0 & Pantomorus & 3 & 100.0 \\
\hline genus & $\mathrm{N}$ of examined & $\%$ of infected & Deronectes & 11 & 45.4 & Polydrosus & 4 & 75.0 \\
\hline Acalymma & 2 & 100.0 & Diabrotica & 12 & 25.0 & Rhantus & 2 & 0.0 \\
\hline Acmaeodera & 5 & 0.0 & Dorytomus & 3 & 67.0 & Rhinusa & 3 & 33.3 \\
\hline Acmaeoderella & 4 & 0.0 & Epilachna & 2 & 0.0 & Sciaphobus & 2 & 50.0 \\
\hline Agabus & 6 & 16.7 & Eurymetopus & 2 & 100.0 & Sitophilus & 3 & 100.0 \\
\hline Agrilus & 34 & 17.6 & Gyrinus & 3 & 33.0 & Sphenoptera & 11 & 9.1 \\
\hline Altica & 16 & 88.0 & Haliplus & 3 & 33.0 & Strophosoma & 3 & 67.0 \\
\hline Anthaxia & 6 & 16.7 & Helophorus & 3 & 0.0 & Trachypteris & 2 & 0.0 \\
\hline Aramigus & 3 & 100.0 & Hydraena & 24 & 33.3 & Trachys & 6 & 16.7 \\
\hline Archarius & 6 & 16.7 & Hydroporus & 5 & 0.0 & Tribolium & 8 & 12.5 \\
\hline Atrichonotus & 2 & 50.0 & Hygrotus & 5 & 20.0 & & & \\
\hline Aulacophora & 3 & 0.0 & Ilybius & 2 & 0.0 & & & \\
\hline
\end{tabular}


Figure 1

Prisma flow-diagram (see Moher et al., 2009) for literature on Wolbachia-Coleoptera relations included in this study.
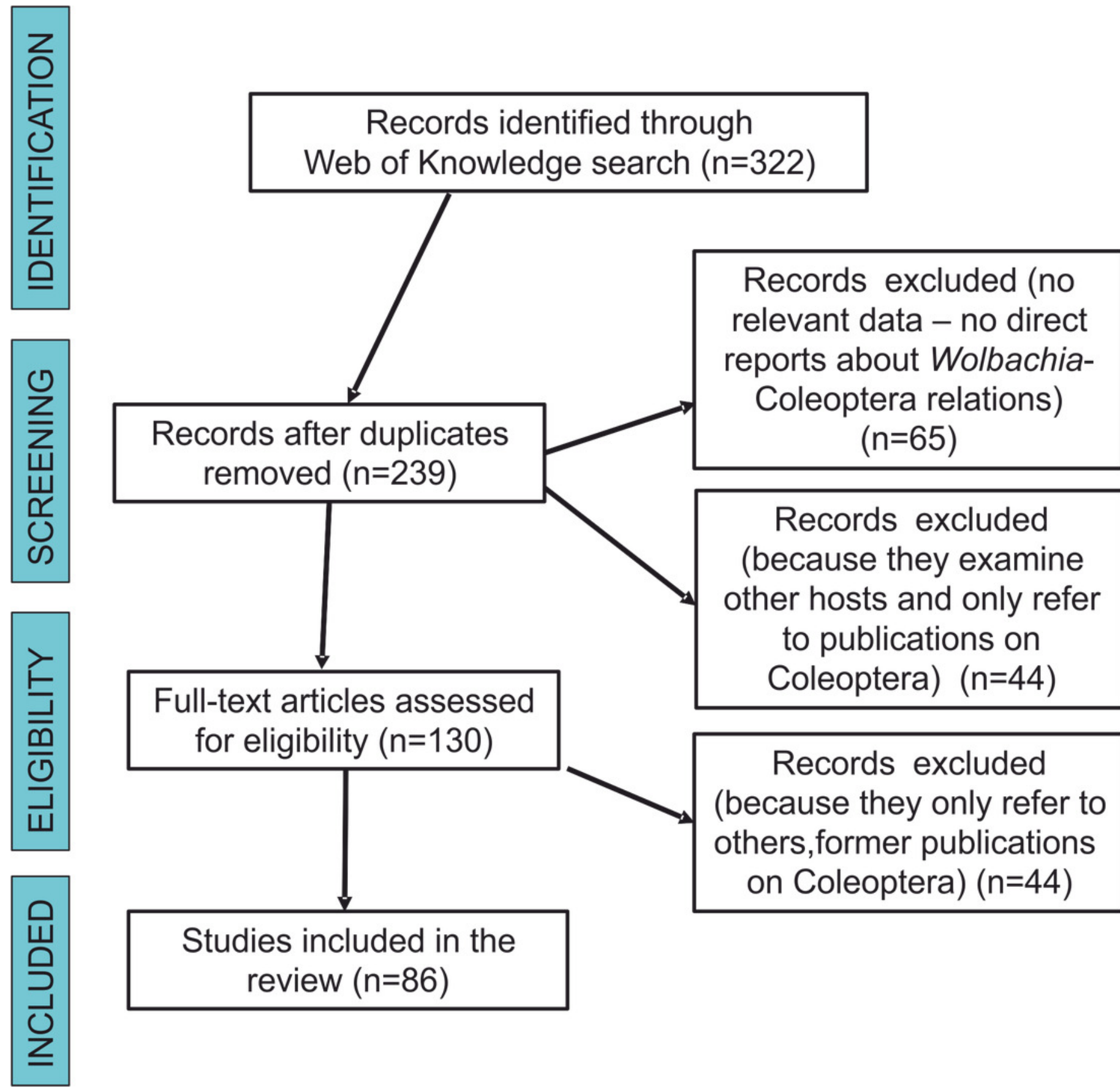

Studies included in the review $(n=86)$ 
Figure 2

Change in the number of publications considering Wolbachia infection among Coleoptera.

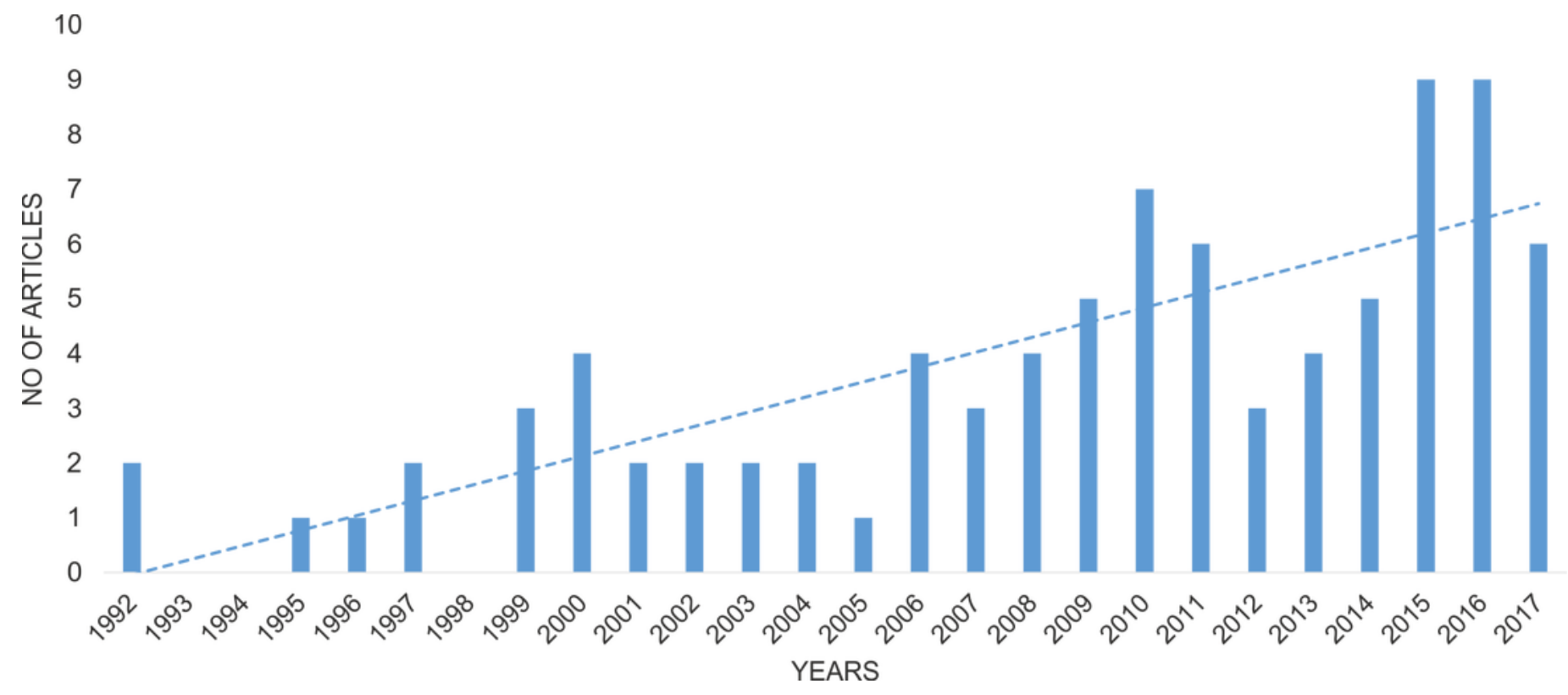




\section{Figure 3}

Number of publications that described Wolbachia infection among Coleoptera and number of infected beetle species.

Both are shown with respect to the zoogeography of the examined hosts (from which continent the host was collected).

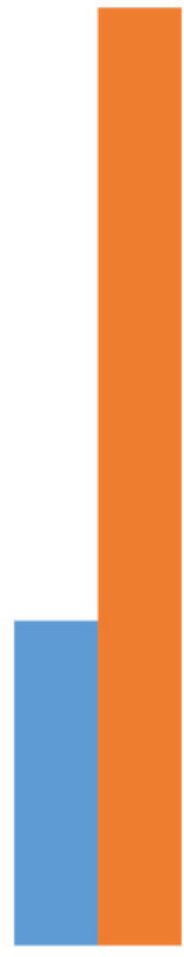

EUROPE

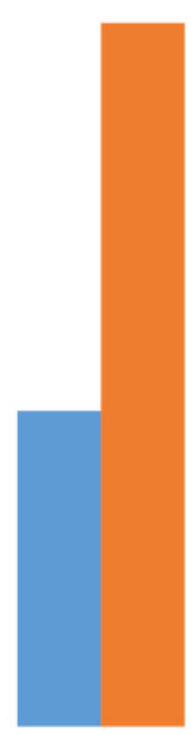

ASIA

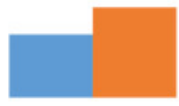

AFRICA

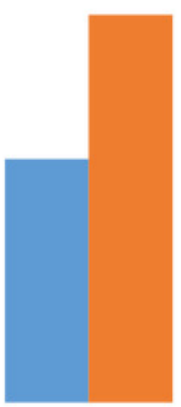

N AMERICA

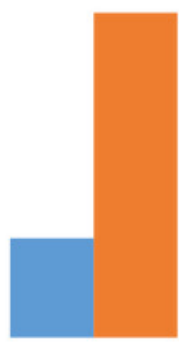

S AMERICA 


\section{Figure 4}

Number of sites (A) and number of individuals (B) of beetles examined with respect to Wolbachia infection.

P - Mann-Whitney test $p$-values.
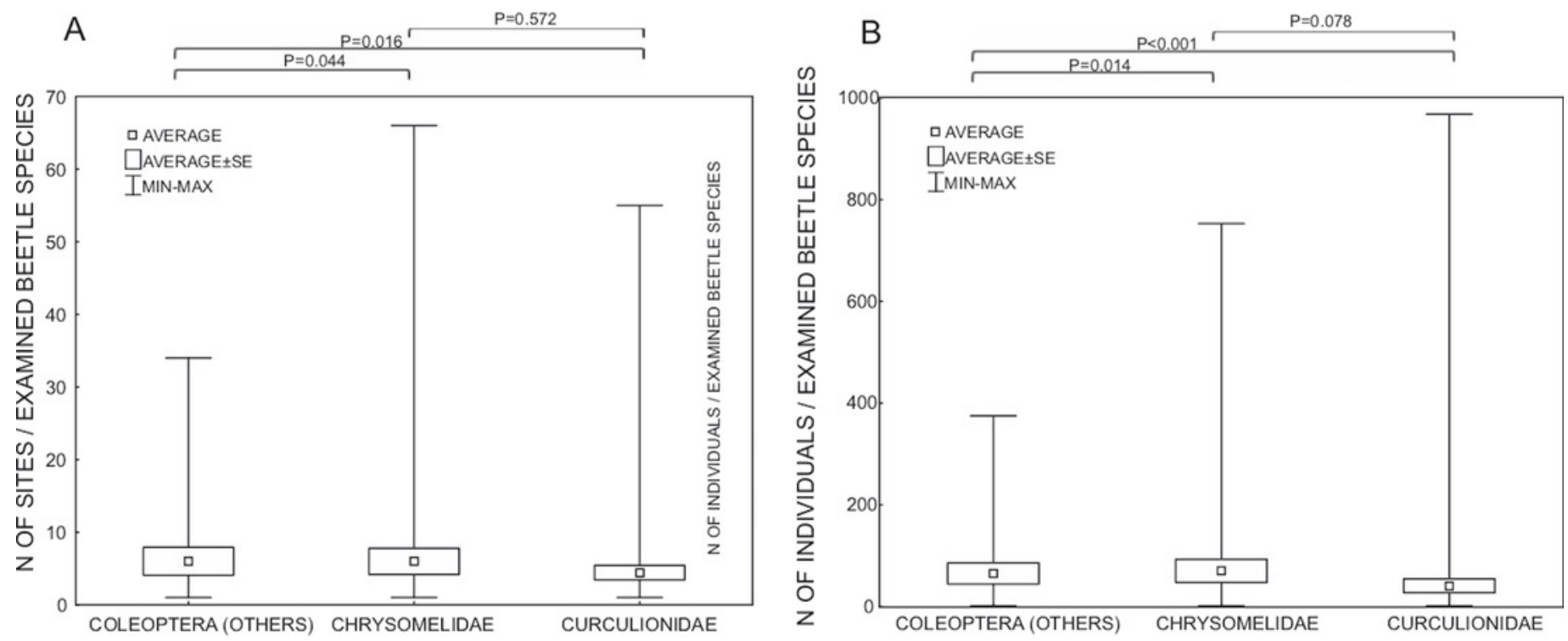


\section{Figure 5}

Shares of Wolbachia genes used in studies on Wolbachia infection among Coleoptera.

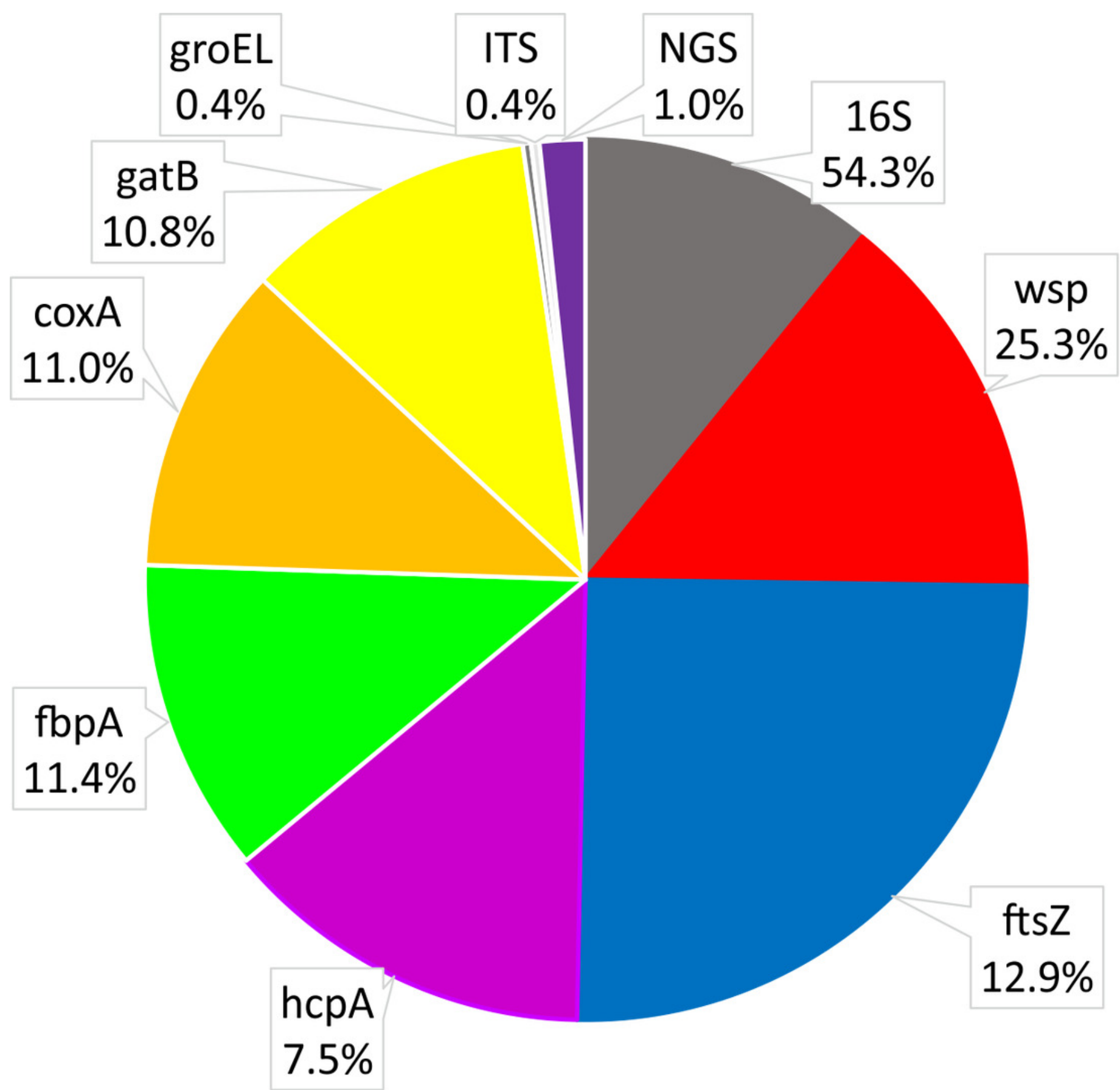




\section{Figure 6}

Shares of Wolbachia infected beetle species across the examined families of Coleoptera.

The numbers presented after the family names indicate the number of infected species.

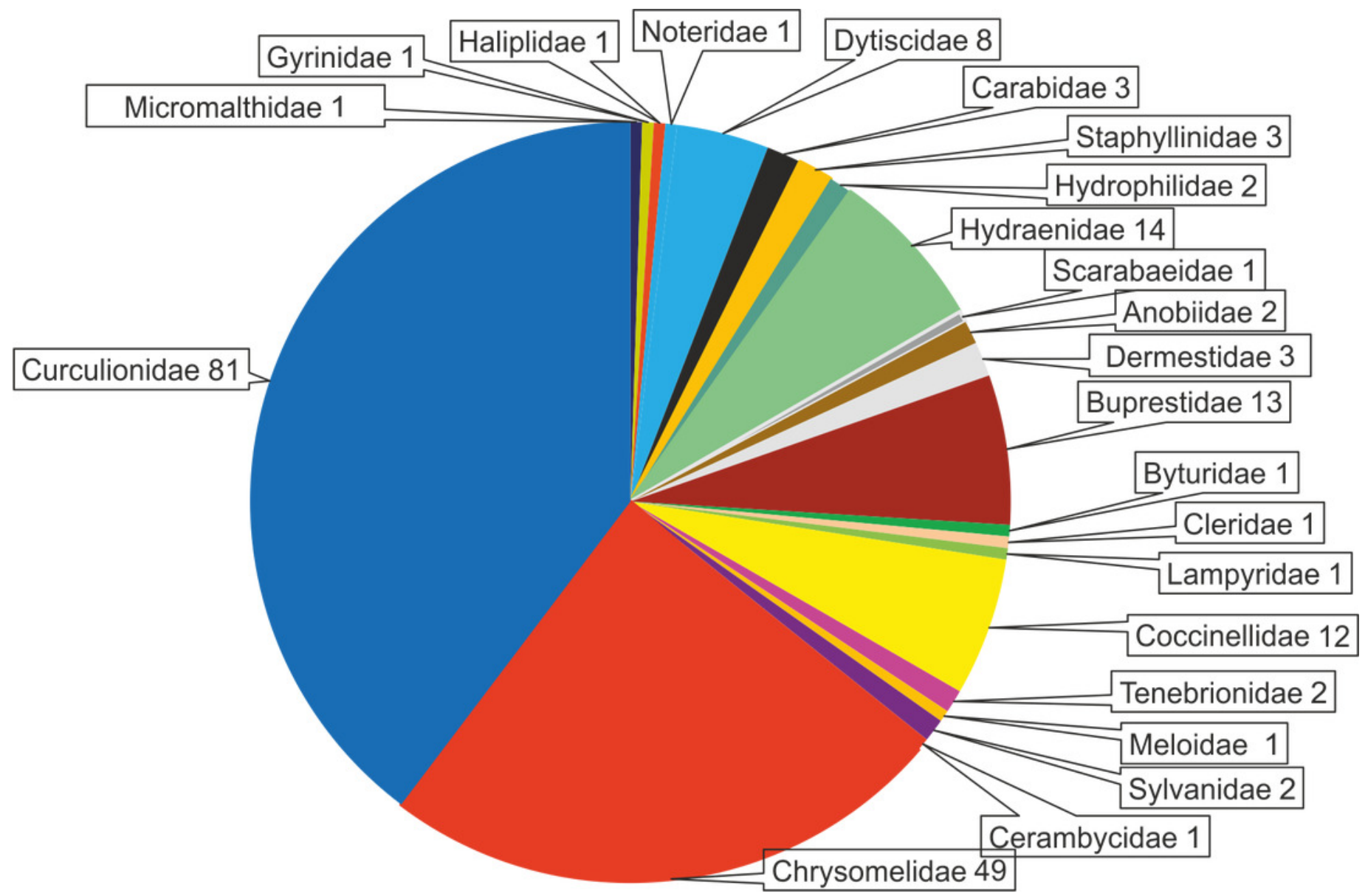




\section{Figure 7}

Shares of beetles infected by Wolbachia supergroups (A, B, F).

[Beetle photographs are from ICONOGRAPHIA COLEOPTERORUM POLONIAE ( $\odot$ Copyright by Prof. Lech Borowiec].

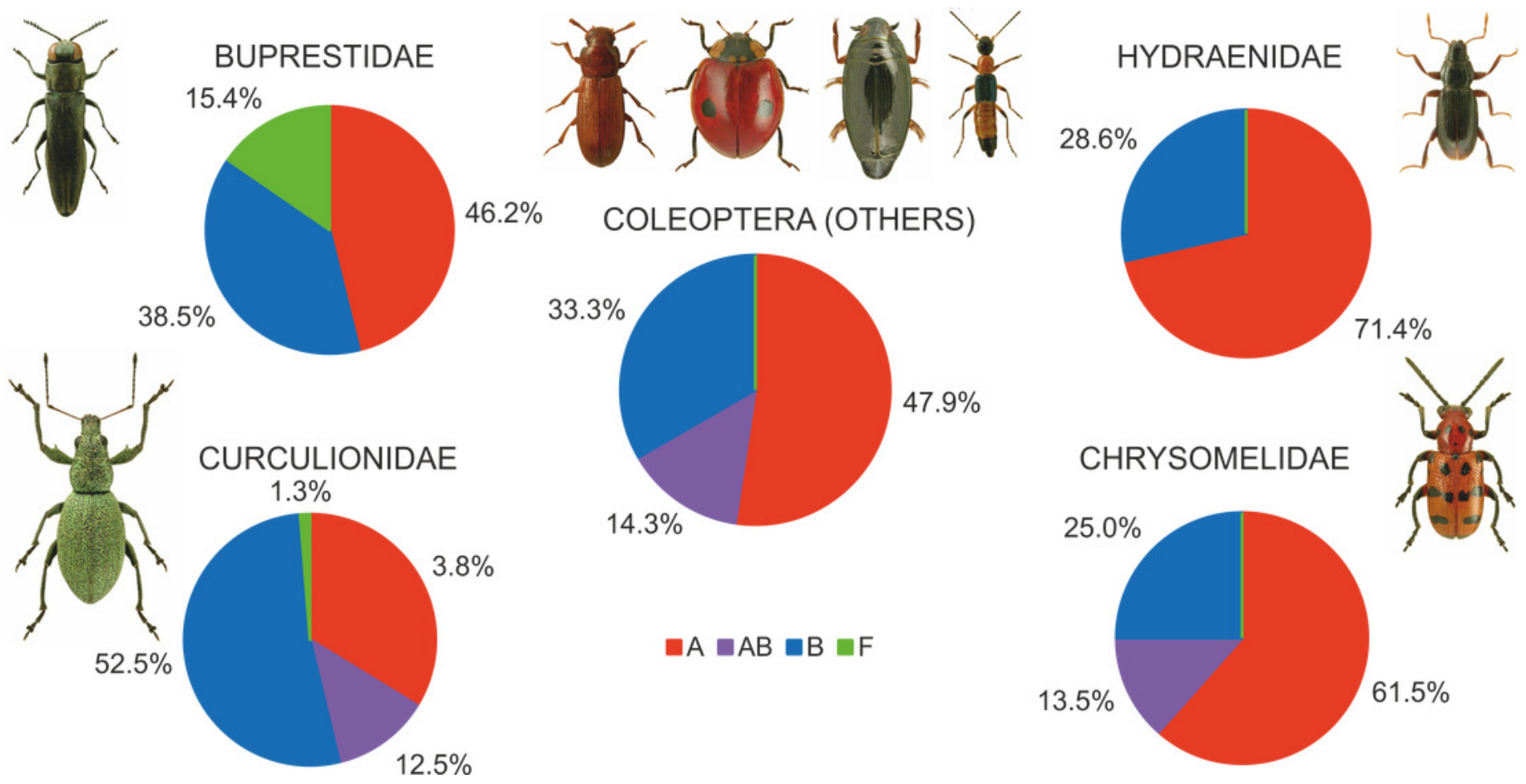


Figure 8

Diversity of Wolbachia infection in Coleoptera with respect to shares of infected individuals within species and numbers of strains found in beetles.

[Beetle photographs are from ICONOGRAPHIA COLEOPTERORUM POLONIAE ( $\odot$ Copyright by Prof. Lech Borowiec]. 


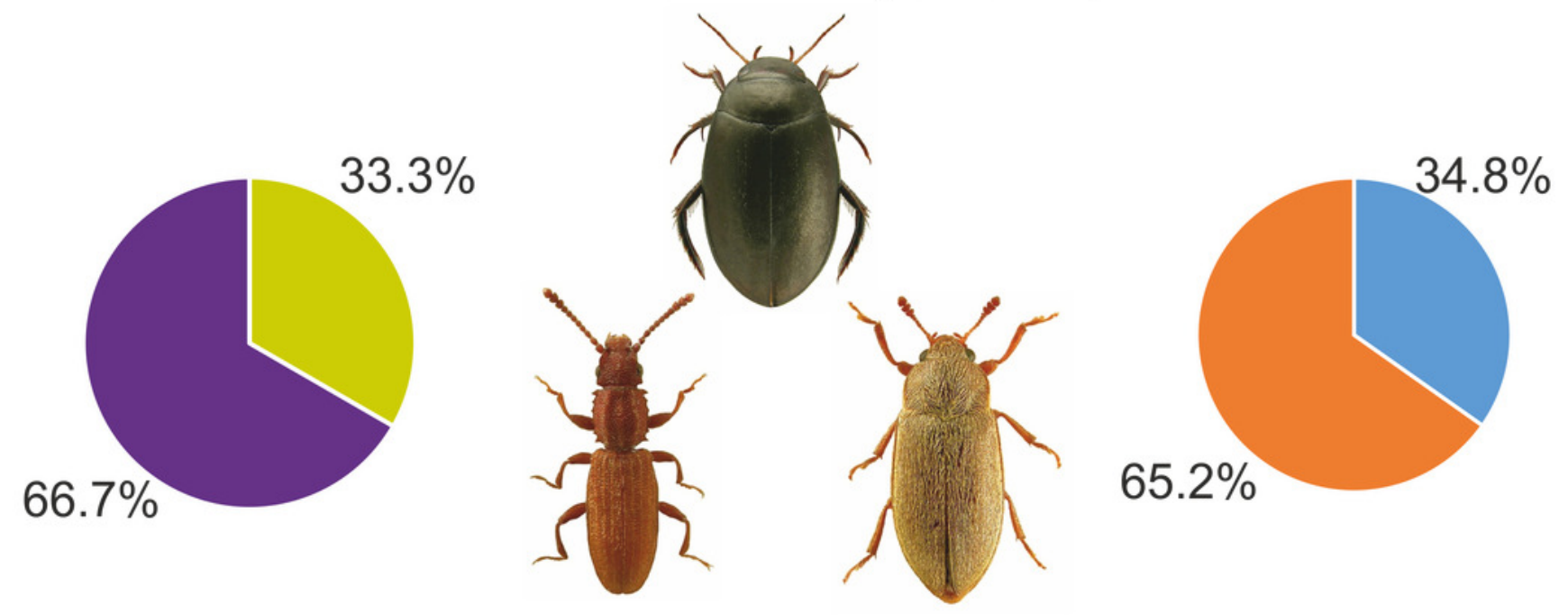

\section{COLEOPTERA (OTHERS)}

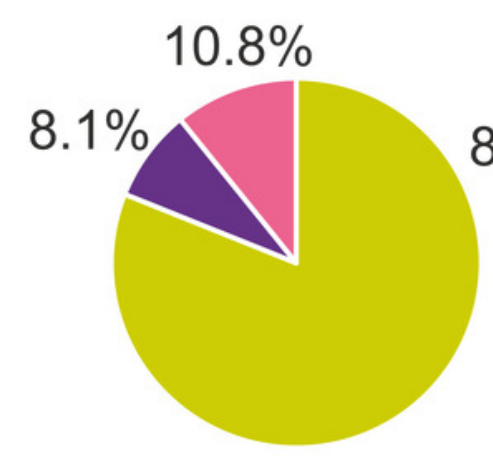

$81.1 \%$

CURCULIONIDAE
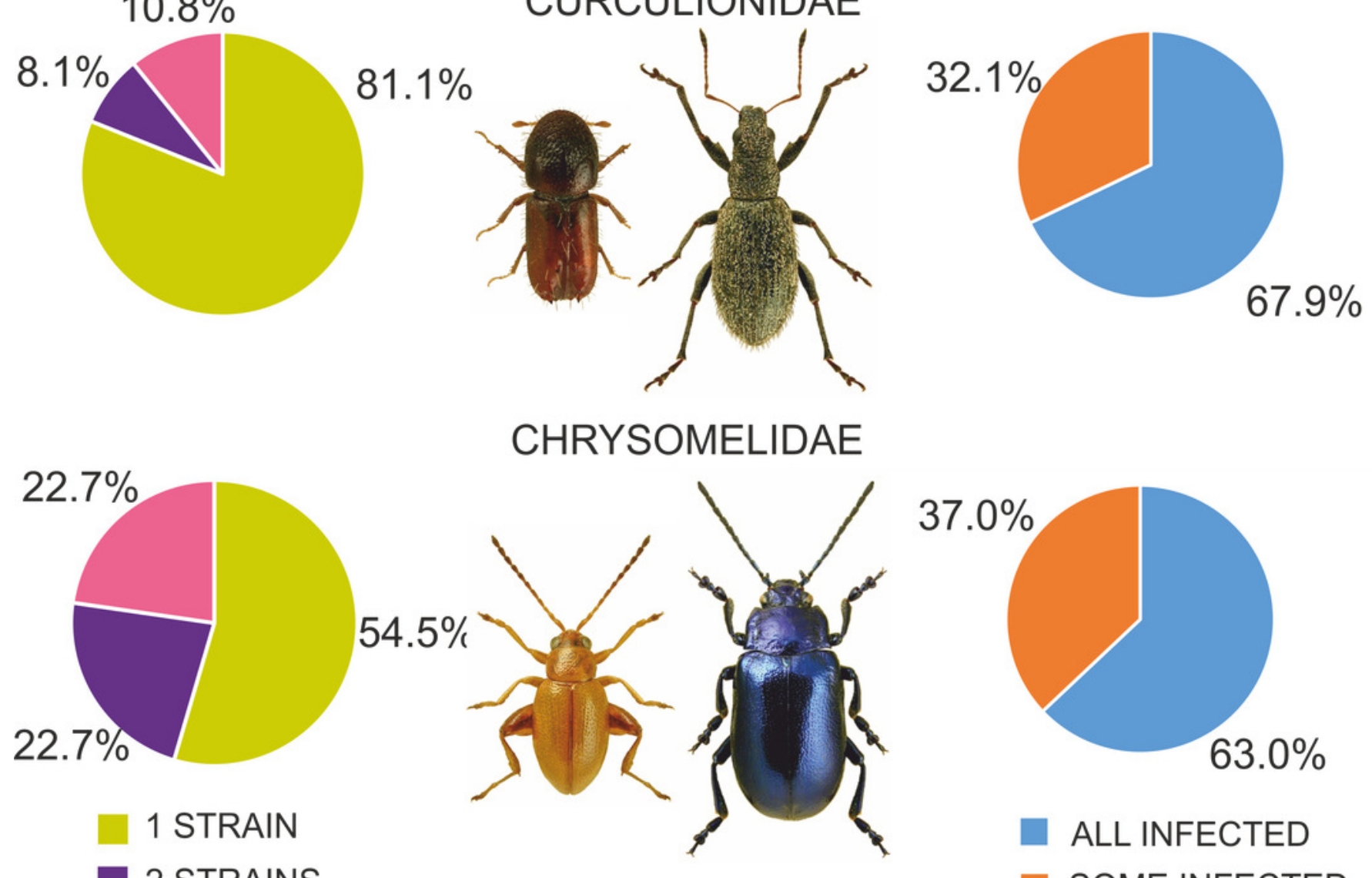

2 STRAINS

ALL INFECTED

MULTIPLE STRAINS 